\title{
Effects of sex and deletion of neuropeptide Y2 receptors from GABAergic neurons on affective and alcohol drinking behaviors in mice
}

\author{
Nora M. McCall ${ }^{1,2+}$, Gretchen M. Sprow ${ }^{1,3+}$, Eric Delpire ${ }^{4,5}$, Todd E. Thiele ${ }^{1,3}$, Thomas L. Kash ${ }^{1,2}$ and \\ Kristen E. Pleil ${ }^{1,2}$ *
}

${ }^{1}$ Bowles Center for Alcohol Studies, University of North Carolina School of Medicine, Chapel Hill, NC, USA

${ }^{2}$ Department of Pharmacology, University of North Carolina School of Medicine, Chapel Hill, NC, USA

${ }^{3}$ Department of Psychology, University of North Carolina at Chapel Hill, Chapel Hill, NC, USA

${ }^{4}$ Department of Anesthesiology, Vanderbilt University, Nashville, TN, USA

${ }^{5}$ Department of Molecular Physiology and Biophysics, Vanderbilt University, Nashville, TN, USA

\section{Edited by:}

Marisa Roberto, The Scripps Research Institute, USA

\section{Reviewed by:}

Nicholas W. Gilpin, Louisiana State

University Health Sciences

Center-New Orleans, USA

Jeff L. Weiner, Wake Forest School of

Medicine, USA

\section{${ }^{*}$ Correspondence}

Kristen E. Pleil, Bowles Center for Alcohol Studies and Department of Pharmacology, University of North Carolina School of Medicine, 104 Manning Drive, Thurston-Bowles Building, Room 5023, CB \#7178,

Chapel Hill, NC 27599, USA

e-mail:kpleil@email.unc.edu

\section{${ }^{\dagger}$ Present address:}

Nora M. McCall, Graduate Program in Neuroscience, University of Minnesota, Minneapolis, MN 55455, USA;

Gretchen M. Sprow, Department of Psychiatry and Behavioral Sciences, Division of Brain Stimulation and Neurophysiology, Duke University School of Medicine, Durham, NC 27710, USA
A large literature has demonstrated that neuropeptide $Y$ (NPY) regulates many emotional and reward-related behaviors via its primary receptors, $Y 1 R$ and $Y 2 R$. Classically, NPY actions at postsynaptic $Y 1 R$ decrease anxiety, depression, and alcohol drinking, while its actions at presynaptic $Y 2 R$ produce the opposite behavioral phenotypes. However, emerging evidence suggests that activation of $\mathrm{Y} 2 \mathrm{R}$ can also produce anxiolysis in a brain region and neurotransmitter system-dependent fashion. Further, numerous human and rodent studies have reported that females display higher levels of anxiety, depression, and alcohol drinking. In this study, we evaluated sex differences and the role of $Y 2 R$ on GABAergic transmission in these behaviors using a novel transgenic mouse that lacks Y2R specifically in VGAT-expressing neurons (VGAT-Y2R knockout). First, we confirmed our genetic manipulation by demonstrating that $Y 2 R$ protein expression was decreased and that a Y2R agonist could not alter GABAergic transmission in the extended amygdala, a limbic brain region critically implicated in the regulation of anxiety and alcohol drinking behaviors, using immunofluorescence and slice electrophysiology. Then, we tested male and female VGAT-Y2R knockout mice on a series of behavioral assays for anxiety, depression, fear, anhedonia, and alcohol drinking. We found that females displayed greater basal anxiety, higher levels of ethanol consumption, and faster fear conditioning than males, and that knockout mice exhibited enhanced depressive-like behavior in the forced swim test. Together, these results confirm previous studies that demonstrate higher expression of negative affective and alcohol drinking behaviors in females than males, and they highlight the importance of $Y 2 R$ function in GABAergic systems in the expression of depressive-like behavior.

Keywords: NPY, anxiety, depression, ethanol, amygdala, female, GABA

\section{INTRODUCTION}

Neuropeptide Y (NPY) is an endogenous "anti-stress" neuropeptide involved in the regulation of several affective and rewardrelated behaviors. Genetic and pharmacological manipulations of central NPY have shown that this peptide plays an important role in anxiety, depression, and alcohol drinking behavior (Heilig et al., 1989; Bannon et al., 2000; Lindell et al., 2010; Tasan et al., 2010; Sparrow et al., 2012). NPY's primary receptors, Y1R and Y2R, are highly expressed throughout the brain (Parker and Herzog, 1999) and NPY signaling via these two G protein-coupled receptors are thought to produce diverging behavioral phenotypes. While Y1R has generally been shown to mediate many of the anxiolytic and anti-drinking effects of NPY (Schroeder et al., 2003; Karlsson et al., 2008; Bertocchi et al., 2011; Sparrow et al., 2012), Y2R has been shown to increase anxiety and alcohol consumption (Tschenett et al., 2003; Bacchi et al., 2006; Tasan et al., 2010; Sparrow et al., 2012). However, there are several reports indicating that NPY's Y2R-mediated behavioral effects are much more complex (Kask et al., 1998; Thiele et al., 2004; Fendt et al., 2009; Zambello et al., 2010; Trent and Menard, 2013). For example, Y2R mediates the anxiolytic effects of NPY in the lateral septum and locus coeruleus (Kask et al., 1998; Trent and Menard, 2013).

Several lines of evidence suggest that the varying behavioral outcomes of Y2R manipulations may depend on the neurotransmitter systems that $\mathrm{Y} 2 \mathrm{R}$ modulate in these regions. Y2R has been described as having an inhibitory role in the release of several neurotransmitters, including glutamate, GABA, norepinephrine, and dopamine, among others (Silva etal., 2005; Zambello etal., 2010). Presynaptic Y2R decreases glutamate release in the hippocampus and decreases GABA release in the 
central nucleus of the amygdala (CeA), and the bed nucleus of the stria terminalis (BNST; Kash and Winder, 2006; Gilpin et al., 2011; Ledri et al., 2011; Pleil et al., 2012), extended amygdala structures particularly implicated in a host of anxiety, depression, and alcohol drinking behaviors (Schroeder et al., 2003; Tasan et al., 2010; Zhang et al., 2010; Gilpin et al., 2011). For example, we have recently shown that stress alters Y2Rmediated modulation of GABAergic transmission in the BNST of stress-susceptible DBA/2J, but not stress-resilient C57BL/6J, mice (Mozhui etal., 2010; Pleil etal., 2012). In the present study, we evaluated the role of Y2R modulation of GABAergic transmission in anxiety, depression, and alcohol drinking behaviors using a transgenic mouse lacking $\mathrm{Y} 2 \mathrm{R}$ in GABAergic neurons.

A robust human literature has shown that females display greater propensity for these affective and drinking behaviors than males (Kessler et al., 1994, 1995; Gater et al., 1998; Lewinsohn et al., 1998a,b; Bekker and van Mens-Verhulst, 2007; Ohrmann et al., 2010). While many rodent studies reveal similar results, particularly in mice on a C57BL/6J background (Kennett et al., 1986; Johnston and File, 1991; Middaugh etal., 1999; Frye et al., 2000; Adamec et al., 2006; Dalla and Shors, 2009; Stack et al., 2010; ter Horst etal., 2012b; Melon etal., 2013), a number of studies report that male rodents exhibit greater anxiety-related behavior, depending on the strain and behavioral assay used (Johnston and File, 1991; Rodgers and Cole, 1993; Zimmerberg and Farley, 1993; Leret et al., 1994; Voikar et al., 2001; Adamec et al., 2006; ter Horst et al., 2012a). Therefore, we used both male and female mice to investigate potential sex differences in these behaviors and the role of GABAergic Y2R.

\section{MATERIALS AND METHODS SUBJECTS}

We generated mice that lack Y2R specifically in GABAergic neurons (VGAT-Y2R knockout) by breeding heterozygous VGATires-Cre mice (Vong et al., 2011) with homozygous Y2R-floxed mice. Y2R-floxed mice were generated using the targeting protocol described in the following section. Female offspring heterozygous for Y2R-flox and vGAT-ires-Cre were bred with male homozygous Y2R-floxed mice. Homozygous Y2R-floxed offspring from this breeding scheme were used in this study; VGAT-ires-Cre +/-, Y2R-floxed +/+ mice had Y2R knocked out from VGAT neurons (VGAT-Y2R KO) and VGAT-ires-Cre -/-, Y2R-floxed +/+ mice did not have altered Y2R expression (VGAT-Y2R control). Mice were group-housed in our colony room with a 12:12-h light-dark cycle with lights on at 7 a.m. Mice had ad libitum access to standard rodent chow and water. All procedures were approved by the Institutional Animal Care and Use Committee of the University of North Carolina at Chapel Hill and performed in accordance with the National Institutes of Health guide for the care and use of laboratory animals. Mice were at least 6 weeks of age at the beginning of the study.

\section{NPY Y2R TARGETING}

Using recombineering, a $2.1 \mathrm{~kb}$ genomic fragment was dropped from BAC clone bMQ-343H17 (Geneservice, Ltd, UK) upstream of a loxP site located in modified pBSK+ vector. This fragment constitutes the left arm of recombination (Figure 1A). Similarly, a $6.3 \mathrm{~kb}$ fragment was dropped from the same BAC clone downstream of a loxP site located in a separate $\mathrm{pBSK}+$ vector containing a neomycin-resistance gene cassette flanked by two FRT and loxP sites. This fragment contains the right arm of recombination. Finally, a $3.1 \mathrm{~kb}$ fragment consisting of exon 2 was dropped to a third pBSK+ vector. The targeting vector was then created by adding the fragment containing the left arm of recombination and the fragment containing the exon to the vector containing the neomycin resistance gene cassette and the right arm of recombination using unique restrictions sites. The construct was linearized with NotI and electroporated in TL-1 embryonic stem (ES) cells. The cells were the plated and grown on fibroblast feeder cells in Dulbecco's modified Eagle medium (DMEM) supplemented with $15 \%$ fetal bovine serum [Life Technologies (formerly Invitrogen), Carlsbad, CA, USA], $50 \mu \mathrm{g} \mathrm{ml}^{-1}$ gentamycin (Invitrogen), 1,000 U ml-1 murine leukemia inhibitory factor [Millipore Biosciences (formerly Chemicon), Temecula, CA, USA], $90 \mu \mathrm{M}$ 2-mercaptoethanol (Sigma-Aldrich, St. Louis, MO, USA) and $0.2 \mathrm{mg} \mathrm{ml}^{-1} \mathrm{G} 418$ (Invitrogen). We picked 494 independent neomycin-resistant colonies and grew them in 96-well plates on a feeder layer, and then expanded the colonies and analyzed them for the presence of the mutated gene. Southern-blot analysis was done using genomic DNA digested with SpeII and hybridized with a ${ }^{32} \mathrm{P}$-labeled probe consisting of a 409-bp PCR fragment located upstream of the left arm of recombination (Figure 1A). Eight clones contained a $6.5-\mathrm{kb}$ SpeI fragment characteristic of the mutated gene (Figure 1B). After further characterization using internal and $5^{\prime}$-end probes, PCR amplification ES cell genomic DNA was then used to assess the presence of the first loxP site. Indeed, as the targeted exon is large, it is likely to participate in the recombination in lieu of the left arm resulting in failure to incorporate the loxP site. In fact, only one clone demonstrated the presence of the loxP site (Figure 1C). This properly recombined ES cell clone was injected into C57BL/6J blastocysts and three chimeric mice with $\sim 90 \%$ brown fur were generated. After confirmation of germline transmission, mice carrying the three loxP allele were mated with $F l p E$ mice to eliminate the neomycinresistance gene cassette. As seen in Figure 1D, mice positive for the FlpE transgene demonstrated presence of the two loxP allele. Homozygous Y2R-floxed mice were then successfully generated by mating heterozygous two loxP mice (Figure 1E). Out of six breeding cages, 55 pups were generated, including 15 homozygotes, 10 controls, and 30 heterozygotes. The distribution was Mendelian as it corresponded to $27(\sim 25 \%), 18(\sim 25 \%)$, and 55\% ( 50\%), respectively. To ensure that the exon could be excised by CRE recombination, females carrying one copy of the two loxP allele were crossed to E2a-CRE mice. Out of 17 pups produced, about $1 / 2$ carried the E2a-CRE transgene and three demonstrated loss of the exon (data not shown).

\section{FUNCTIONAL AND ANATOMICAL CONFIRMATION OF GENETIC MANIPULATION \\ Slice electrophysiology}

To examine the effects of NPY on evoked GABAergic transmission in the BNST, we performed whole-cell voltage-clamp 

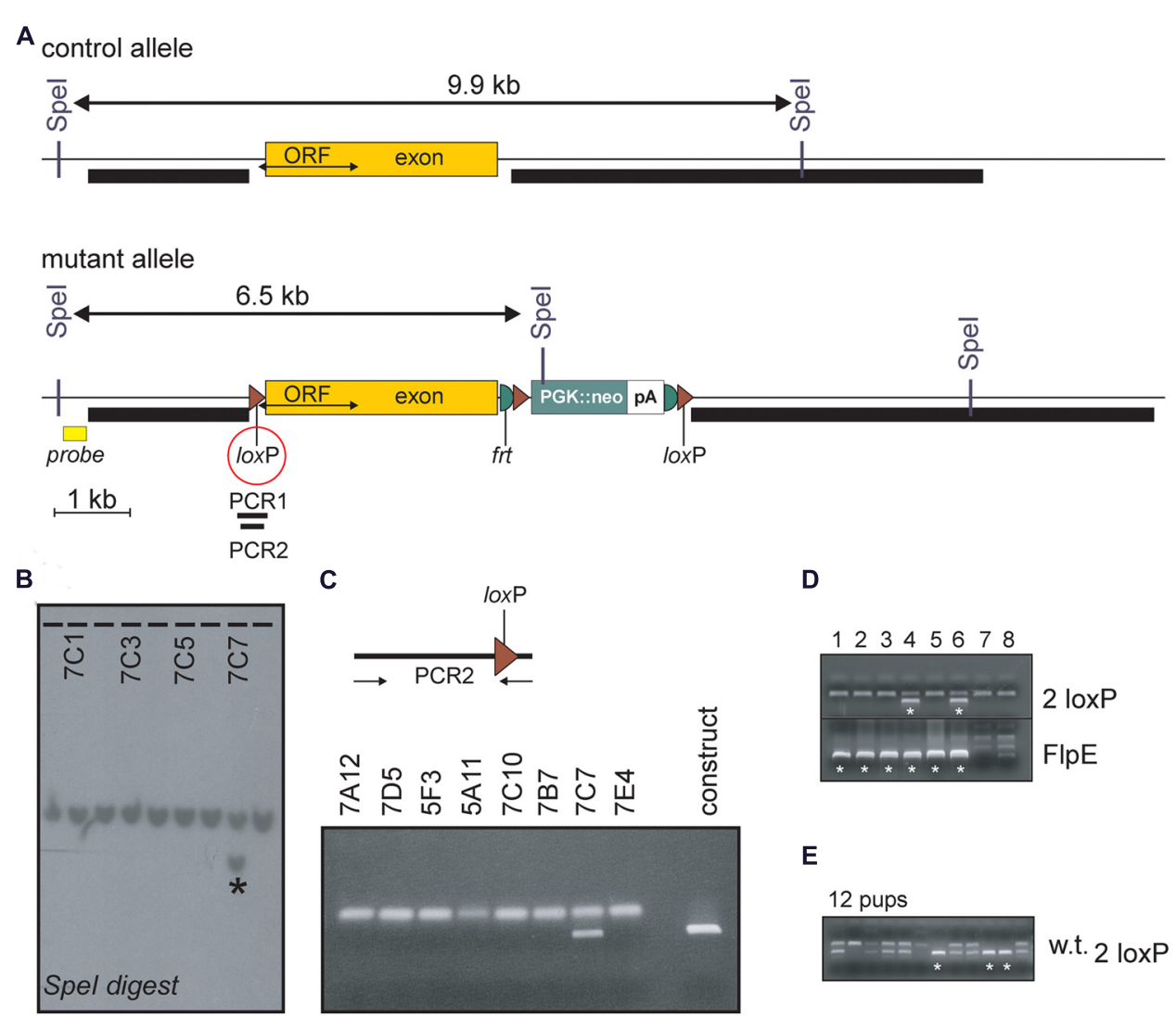

FIGURE 1 | Disruption of mouse NPY Y2R. (A) Structure of the NPYY2R control and mutant alleles around exon 2. The entire Open Reading frame (ORF) of the receptor is contained within the exon. Position of the $5^{\prime}$ probe, of the short and long arms of recombination (thick black bars), of loxP and FRT sites, and of Spel restriction sites are indicated. The first loxP site, which is at risk of not being included during recombination, is highlighted by a red circle. Presence of this loxP site is verified by PCR amplification of ES cell genomic DNA (PCR1 and PCR2). (B) Portion of the Southern blot analysis of ES-cell genomic DNA digested with Spel and probed with the $5^{\prime}$ probe. Signals are from clones 7B12 to 7C8. The wild-type gene shows across as a band of $\sim 10 \mathrm{~kb}$ whereas a $6.5 \mathrm{~kb}$ additional band is observed in clone 7C7. (C) Presence of the loxP site is confirmed in ES cell clone 7C7. The construct serves as positive control. (D) Elimination of the neomycin resistance gene cassette is illustrated in two mice by the presence of the F/pE transgene (stars) and the presence of a larger band in samples 4 and 6 (also indicated by stars).

(E) PCR genotyping of 21-day old pups demonstrating that viable Y2R-floxed mice were successfully generated. PCR yielded two samples with a single small band (wild-type mice), seven samples with two bands (heterozygous two loxP mice) and three samples with a single large band (stars, homozygous two loxP mice). electrophysiological recordings in dorsal BNST neurons from acutely prepared coronal brain slices, as previously described (Li et al., 2012; Pleil et al., 2012), of VGAT-Y2R mice. Briefly, mice were decapitated under isoflurane anesthesia, and their brains were rapidly removed and placed in ice-cold sucrose-artificial cerebrospinal fluid (ACSF) containing: (in mM) 194 sucrose, 20 $\mathrm{NaCl}, 4.4 \mathrm{KCl}, 2 \mathrm{CaCl}_{2}, 1 \mathrm{MgCl}_{2}, 1.2 \mathrm{NaH}_{2} \mathrm{PO}_{4}, 10.0$ glucose, and $26.0 \mathrm{NaHCO}_{3}$ saturated with $95 \% \mathrm{O}_{2} / 5 \% \mathrm{CO}_{2}$. Coronal slices $300 \mu \mathrm{m}$ in thickness containing the dorsal BNST (Bregma $0.26-0.02 \mathrm{~mm}$ ) were sectioned on a Leica VT1200 vibratome and stored in a holding chamber with $28-30^{\circ} \mathrm{C}$, oxygenated ACSF containing [(in mM) $124 \mathrm{NaCl}, 4.4 \mathrm{KCl}, 2 \mathrm{CaCl}_{2}, 1.2 \mathrm{MgSO}_{4}$, $1 \mathrm{NaH}_{2} \mathrm{PO}_{4}, 10.0$ glucose, and $\left.26.0 \mathrm{NaHCO}_{3}\right]$. Slices were transferred to a submerged recording chamber (Warner Instruments, Hamden, CT, USA), where they were perfused with heated, oxygenated $\operatorname{ACSF}\left(28-30^{\circ} \mathrm{C}\right)$ at a rate of approximately $2 \mathrm{ml} / \mathrm{min}$ and allowed to equilibrate for $30 \mathrm{~min}$ before electrophysiological recordings.
Recording electrodes (3-5 M $\Omega$ ) were pulled with a FlamingBrown Micropipette Puller (Sutter Instruments, Novato, CA, USA) using thin-walled borosilicate glass capillaries. Electrodes were filled with (in $\mathrm{mM}$ ) $70 \mathrm{KCl}, 65 \mathrm{~K}^{+}$-gluconate, $5 \mathrm{NaCl}, 10$ HEPES, 0.6 EGTA, 4 ATP, 0.4 GTP, pH 7.2, 290-295 mOsmol. To block postsynaptic sodium spikes, lidocaine $N$-ethyl bromide $(1 \mathrm{mg} / \mathrm{ml})$ was included in the intracellular recording solution. Neurons were held at $-70 \mathrm{mV}$ and electrically evoked $\mathrm{GABA}_{\mathrm{A}}$ receptor $\left(\mathrm{GABA}_{\mathrm{A}} \mathrm{R}\right)$-mediated inhibitory postsynaptic currents (eIPSCs) were pharmacologically isolated during recordings by adding $3 \mathrm{mM}$ kynurenic acid (Abcam, Cambridge, UK) to the bath solution to block AMPA and NMDA receptor-dependent postsynaptic currents.

Twisted nichrome wire stimulating electrodes were placed dorsal to the recording electrode, $100-500 \mu \mathrm{m}$ medial from the recorded neuron. eIPSCs were evoked at $0.1 \mathrm{~Hz}$ by local fiber stimulation with bipolar electrodes (5-50 V with a 100-150 $\mu \mathrm{s}$ duration) once every $10 \mathrm{~s}$. Signals were acquired via a Multiclamp 
700B amplifier and analyzed using Clampfit 10.3 software (Molecular Devices, Sunnyvale, CA, USA). After at least $5 \mathrm{~min}$ in which mean peak eIPSC amplitude was stable ("baseline period"), NPY (Abcam, Cambridge, UK), stocked in distilled water was diluted to $300 \mathrm{nM}$ in the bath solution and applied to the bath for $10 \mathrm{~min}$, followed by a washout period of at least $5 \mathrm{~min}$. This concentration of NPY has previously been demonstrated to be maximally effective in slices from naïve mice in our lab and other labs (Kash and Winder, 2006; Chee et al., 2010; Pleil et al., 2012). Experiments were analyzed by measuring the peak amplitude of the synaptic response, which was normalized to the baseline period. Input resistance and access resistance were continuously monitored during all experiments, and those in which changes in access resistance were greater than $20 \%$ were not included in the data analysis.

\section{Fluorescence immunohistochemistry}

Mice were anesthetized with Avertin and perfused intracardially with $0.01 \mathrm{M}$ phosphate buffer saline (PBS) followed by $4 \%$ paraformaldehyde (PFA) in PBS. Brains were extracted and postfixed for $24 \mathrm{~h}$ in $4 \%$ PFA, then rinsed twice with PBS and immersed in $30 \%$ sucrose until saturated. Brains were hemisected and coronal slices $45 \mu \mathrm{m}$ in thickness containing the BNST and CeA were prepared using a Leica VT1200 vibratome (Leica Microsystems, Nussloch, Germany).

All steps were performed at room temperature unless stated otherwise, using protocols included in the TSA amplification kit (Perkin Elmer, Waltham, MA, USA). Slices containing BNST and CeA were incubated in primary solution containing $0.3 \%$ Triton $\mathrm{X}-100,0.5 \%$ bovine serum albumin, and an anti-Y2R antibody (1:3000; Neuromics, Edina, MN, USA) for $24 \mathrm{~h}$ at $4^{\circ} \mathrm{C}$. Slices were washed in TNT buffer solution containing Tris/ $\mathrm{HCl}, \mathrm{NaCl}$, and Tween 20 for 10 min followed by TNB blocking solution containing TNT buffer with $0.5 \%$ blocking reagent provided in the TSA kit for $30 \mathrm{~min}$. Slices were washed in TNB solution containing horseradish peroxidase (1:200) for $30 \mathrm{~min}$ and rinsed in TNT buffer. Sections were incubated in Cy3 (1:50) in amplification diluents provided in the TSA kit for $10 \mathrm{~min}$ and then rinsed in TNT buffer. All slices were mounted onto glass slides, allowed to dry, coverslipped with VectaShield (Vector Laboratories, Burlingame, CA, USA), and stored in the dark at $4^{\circ} \mathrm{C}$.

Images of Y2R-IR in the BNST and CeA were obtained with an Olympus FV1000 inverted confocal microscope with a $10 \times$ objective and Olympus FluoView software. All serial sections throughout the BNST and CeA were used for quantification of Y2R-IR using ImageJ Software (National Institute of Health, Bethesda, MD). A contour was drawn around the dorsal BNST or CeA section to be analyzed; intensity values for all serial sections for each mouse were averaged to obtain one value per mouse for the BNST and CeA.

\section{BEHAVIOR}

Behavioral assays for anxiety-like and depressive-like behaviors, as well as behavioral reactivity, were conducted at the UNC Mouse Behavioral Phenotyping Core during the lights-on phase of the day. Binge-like ethanol drinking was conducted in the home cage during the lights-off phase of the day using the standard Drinkingin-the-Dark (DID) paradigm, and ethanol and sucrose preference tests were conducted in the home cage across both phases of the light cycle.

\section{Elevated plus maze}

We used a standard elevated plus maze to assess anxiety-like behavior. Mice were placed in the center section facing an open arm and were allowed to freely explore the maze for $5 \mathrm{~min}$. The number of entries into and time spent in open and closed arms of the apparatus was hand-scored by the experimenter.

\section{Open field test}

The open field test was used to assess general locomotor activity and anxiety-like behavior. Mice were placed in the corner of a $40 \mathrm{~cm} \times 40 \mathrm{~cm} \times 30 \mathrm{~cm}$ open field box (Versamax system, AccuScan Instruments) and allowed to freely explore the arena for $30 \mathrm{~min}$. Behavioral testing boxes were contained inside soundattenuating boxes with house lights and fans. Activity and position were tracked using beam breaks in the AccuScan Fusion Activity System and used to calculate distance traveled and time spent in the center of the field.

\section{Light/dark box}

The light/dark box was used to assess anxiety-like behavior. Mice were placed in the dark side of a $40 \mathrm{~cm} \times 40 \mathrm{~cm} \times 30 \mathrm{~cm}$ box containing light-dark box inserts (Versamax system, AccuScan Instruments) and allowed to freely explore the chamber for $15 \mathrm{~min}$. Behavioral testing boxes were contained inside sound-attenuating boxes with houselights and fans. Activity and location were tracked using beam breaks in the AccuScan VersaMax240 Activity System and VersaMap programs and used to calculate time spent in each side of the chamber.

\section{Forced swim test}

We used the standard forced swim test to measure depressive-like behavior. Mice were placed in clear plexiglass cylinders containing $23^{\circ} \mathrm{C}$ water for $6 \mathrm{~min}$. Video was recorded using EthoVision XT 7 and immobility during the last $4 \mathrm{~min}$ was hand-scored by the experimenter using Ethovision's The Observer XT 10.

\section{Acoustic startle response}

Mice were assessed for basal behavioral reactivity by testing their startle response to an auditory stimulus, as previously described (Brunssen et al., 2013) using a San Diego Instruments SR-Lab system. Mice were placed into restraint tubes and given $5 \mathrm{~min}$ to habituate to the tubes and background noise of $70 \mathrm{~dB}$, followed by six trials of a 40 ms auditory cue of $120 \mathrm{~dB}$, separated by $80 \mathrm{~ms}$. Startle amplitude was collected across a $65 \mathrm{~ms}$ sampling window for each trial.

\section{Contextual and cued fear conditioning and memory}

Mice were assessed for learning and memory of conditioned fear, as previously described (Huang etal., 2013), using the NearInfrared image tracking system (MED Associates, Burlington, VT, USA). On the first day of this three-day test, mice were placed in a sound-attenuating box and allowed to explore for 2 min before three exposures to a 30-s tone of $90 \mathrm{~dB}$ (conditioned stimulus; CS), followed by a two-sec scrambled foot shock of $0.6 \mathrm{~mA}$ (unconditioned stimulus; US) separated by a random interval. Freezing behavior during the tone was quantified by 
the Near-Infrared image tracking system. On the second test day, mice were placed back in the original test chamber and freezing to the context in the absence of the tone presentation was assessed for $5 \mathrm{~min}$. On the third test day, the chambers were modified using a novel odor and inserts to change the surface of the chamber's walls and floors. After 2 min of habituation, the mice were presented with the CS for $3 \mathrm{~min}$ to assess freezing to the cue.

\section{Drinking in the dark procedure}

We used the standard 4-day DID, a well-established animal model of human binge drinking that generates high blood ethanol concentrations (BECs; $\geq 80 \mathrm{mg} / \mathrm{dl}$ ) and has been used to characterize neuromodulators of binge-like ethanol consumption (Sparta et al., 2008; Lowery-Gionta et al., 2012; Sparrow et al., 2012). Three hours into the dark cycle, home cage water bottles were replaced with bottles containing a $20 \%(v / v)$ ethanol solution for $2 \mathrm{~h}$ on Days $1-3$ and $4 \mathrm{~h}$ on Day 4 (binge test day). Tail blood was collected immediately following ethanol access on Day 4 to evaluate BECs.

\section{Sucrose and ethanol preference tests}

We conducted a sucrose preference test to assess whether deletion of Y2R from GABA neurons induced anhedonia in mice. At the beginning of the dark cycle, mice were presented with two bottles, one containing water and the other containing a $1 \%(w / v)$ sucrose solution, for $24 \mathrm{~h}$. Volume of each bottle's contents was used to evaluate the degree to which mice preferred sucrose to water. We also conducted a 24-h ethanol preference test in the same manner, except that $20 \%$ ethanol $(v / v)$ was used instead of sucrose and the two-bottle choice began $3 \mathrm{~h}$ into the dark cycle.

\section{STATISTICAL ANALYSIS}

Appropriate statistical analyses were used to evaluate the effects of sex and Y2R deletion from GABA neurons, including two-way (sex x genotype) ANOVAs. Post hoc t-tests with Bonferroni corrections for multiple comparisons to protect against Type 1 error were conducted to make direct comparisons between groups when ANOVAs revealed significant interactions.

\section{RESULTS \\ ELECTROPHYSIOLOGY AND FLUORESCENCE IMMUNOHISTOCHEMISTRY}

We performed analyses of NPY and Y2R content and function to evaluate the effects of deletion of Y2R from GABA neurons on the function of extended amygdala brain regions critical for anxiety, depression, alcohol drinking, and fear behaviors studied here. We found that in the BNST, the ability of NPY to decrease evoked GABAergic transmission, which we have previously demonstrated occurs via Y2R (Kash and Winder, 2006; Pleil et al., 2012), was present in control Y2R-floxed mice [Figures 2A,B; $t(7)=9.01$, $p<0.0001$ ] but completely absent in $\mathrm{KO}$ mice [Figures 2A,C; $p>0.55$ ], producing a significant difference between control and $\mathrm{KO}$ mice $[t(12)=2.97, p=0.012]$. Interestingly, Y2R-IR was decreased in the $\mathrm{CeA}$ in $\mathrm{KO}$ mice compared to controls [Figures 3A,B; $t(6)=3.17, p=0.019$ ] but not altered in the BNST (Figures 3A,C; $p>0.50$ ), even though Y2R function was ablated in $\mathrm{KO}$ mice (Figure 2).

\section{BEHAVIOR}

\section{Elevated plus maze}

Two-way ANOVAs revealed that neither sex, genotype, nor their interaction affected any measure of anxiety or locomotion in the EPM (Figure 4), including entries to open arms, closed arms, and total arms ( $p$ 's $>0.05)$, or percent time spent in open arms ( $p$ 's $>0.35)$.

\section{Open field test}

In the open field test, females displayed more anxiety-like behavior than males (Figure 5). While groups did not differ in the total distance traveled during the open field test (Figures 5A,B; $p$ 's $>0.35$ ), males spent a significantly greater percent of time in the center of the arena than females (Figures 5C,D), revealed by a main effect of $\operatorname{sex}[F(1,38)=7.25, p=0.011)]$ but no effect of genotype or interaction ( $p$ 's $>0.10)$. This sex difference in anxiety-like behavior was recapitulated in the analysis of percent distance traveled in the center of the arena, which also revealed a main effect of sex $[F(1,38)=4.67, p=0.037$; data not shown $]$ but no other effects ( $p$ 's $>0.15)$.

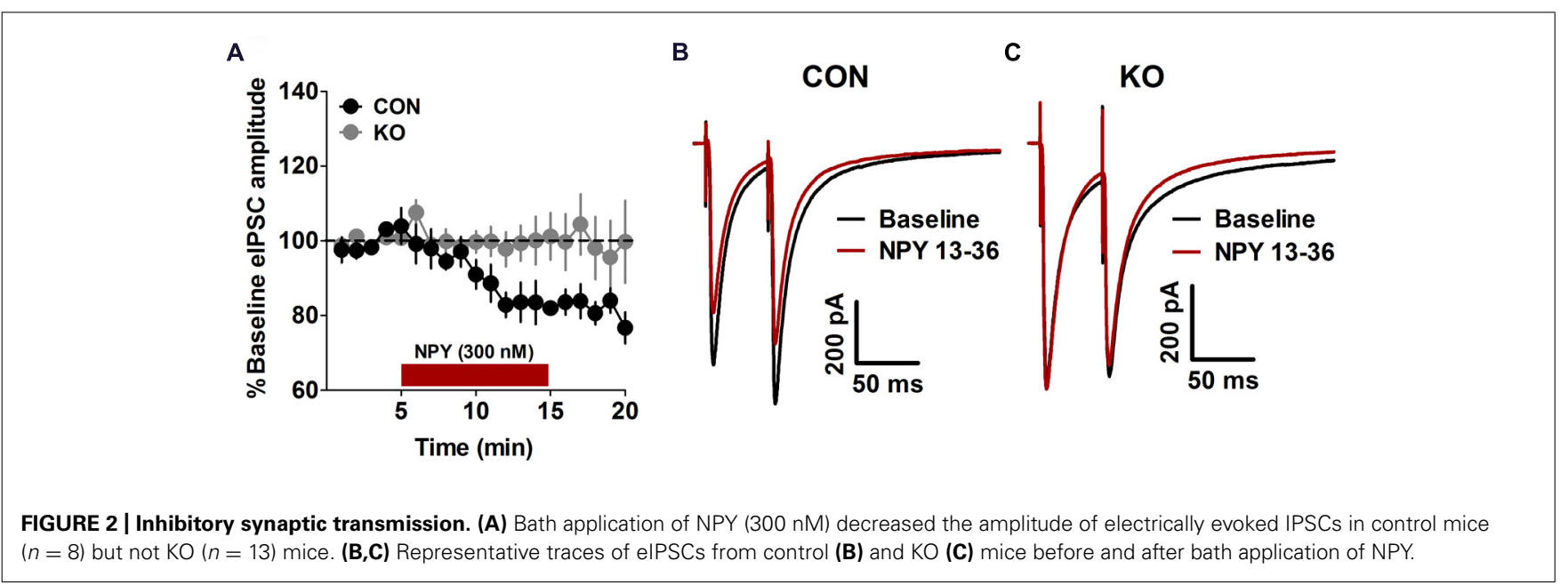



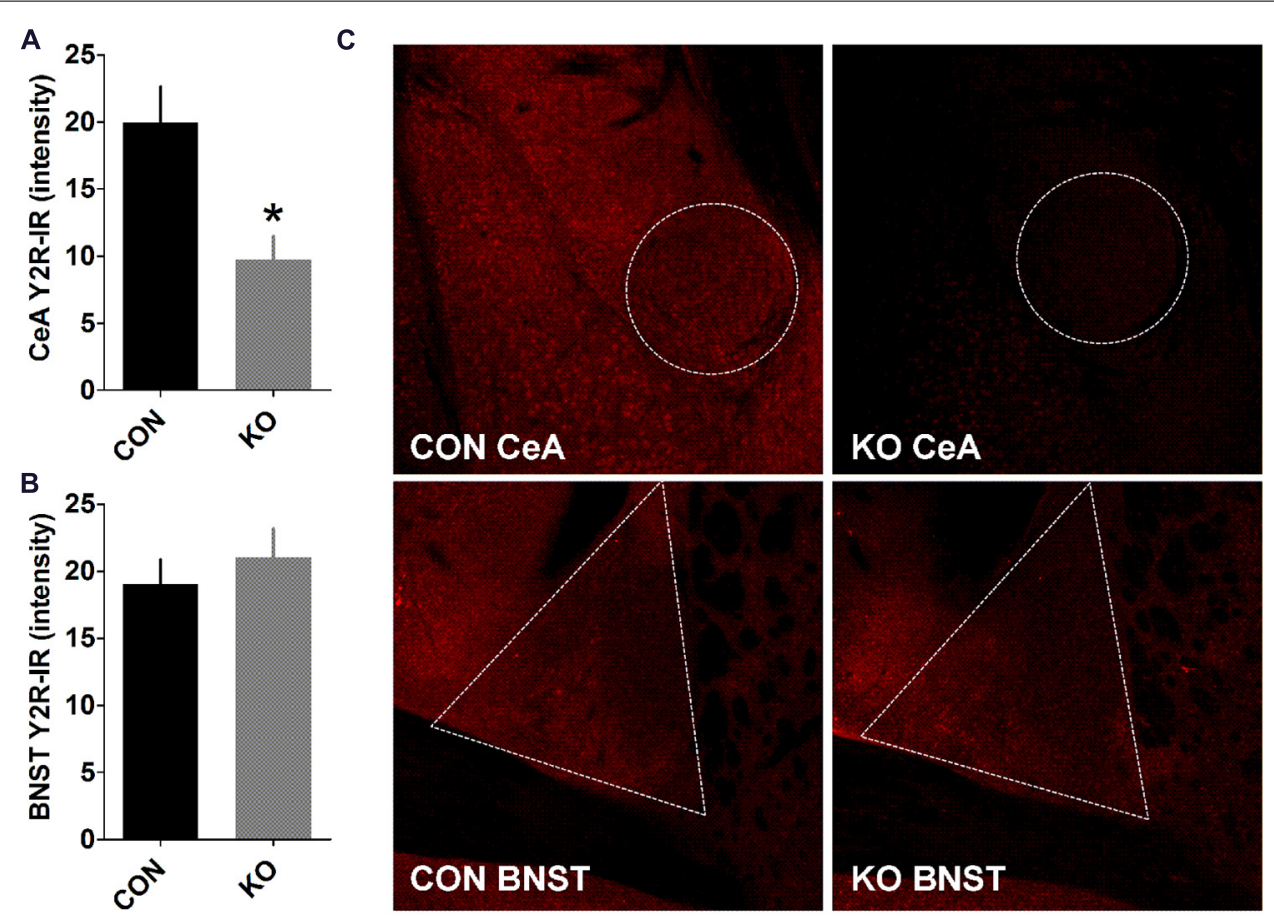

FIGURE 3 |Y2R-immunoreactivity in the CeA and BNST. (A,B) Y2R-IR is decreased in the CeA (A) but not BNST (B) of KO mice compared to controls $\left({ }^{*} p<0.05, n ' s=4\right.$ per group). (C) Representative images taken with a $10 \times$ objective of $Y 2 R-I R$ in the CeA and BNST in control and KO mice, with a border highlighting the quantified regions.
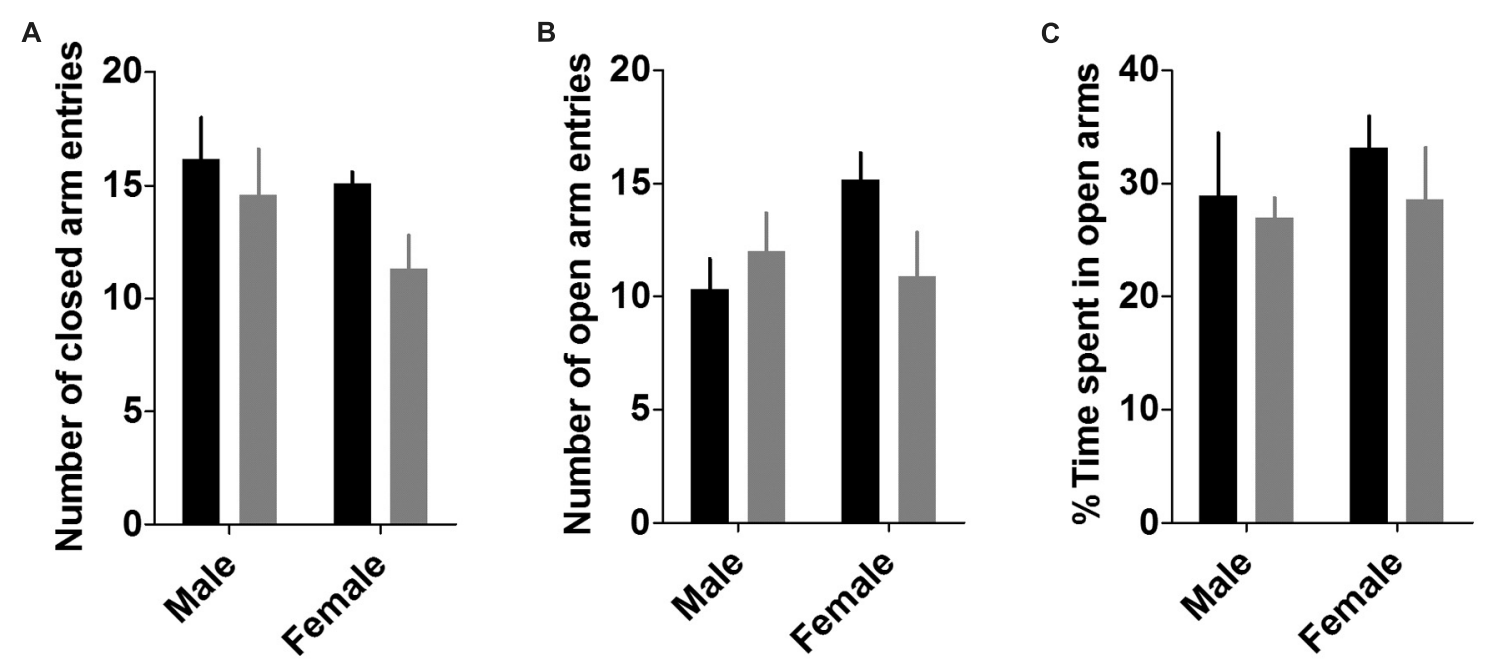

FIGURE 4 | Elevated plus maze. There were no effects of sex or genotype on any measures of locomotion or anxiety in the elevated plus maze, including number of closed arm entries $(\mathbf{A})$, number of open arm entries $(\mathbf{B})$, and the percent time spent in the open arms $(\mathbf{C} ; n ' \mathrm{~s}$ : CON male $=6, \mathrm{KO}$ male $=6, \mathrm{CON}$ female $=11, \mathrm{KO}$ female $=10$ ).

\section{Light/dark box}

Similar to the open field test, analyses of light/dark box measures showed that females displayed more anxiety-like behavior than males (Figure 6). Males displayed more locomotor activity in the light side $[F(1,38)=13.29, p=0.0008]$ but not the dark side (Figure 6A; $p>0.35$ ) than females, leading to a greater percentage of their total locomotion $[F(1,38)=13.39$, $p=0.0008$ ] and time in the light side than females [Figure 6B; $F(1,38)=17.36, p=0.0002]$. Males also had a greater number of entries to the light side [Figure 6C; $F(1,38)=7.71$, $p=0.009$ ] and a shorter latency to enter the light side for the first time during the test [Figure 6D; $F(1,38)=5.06, p=0.030$ ] 

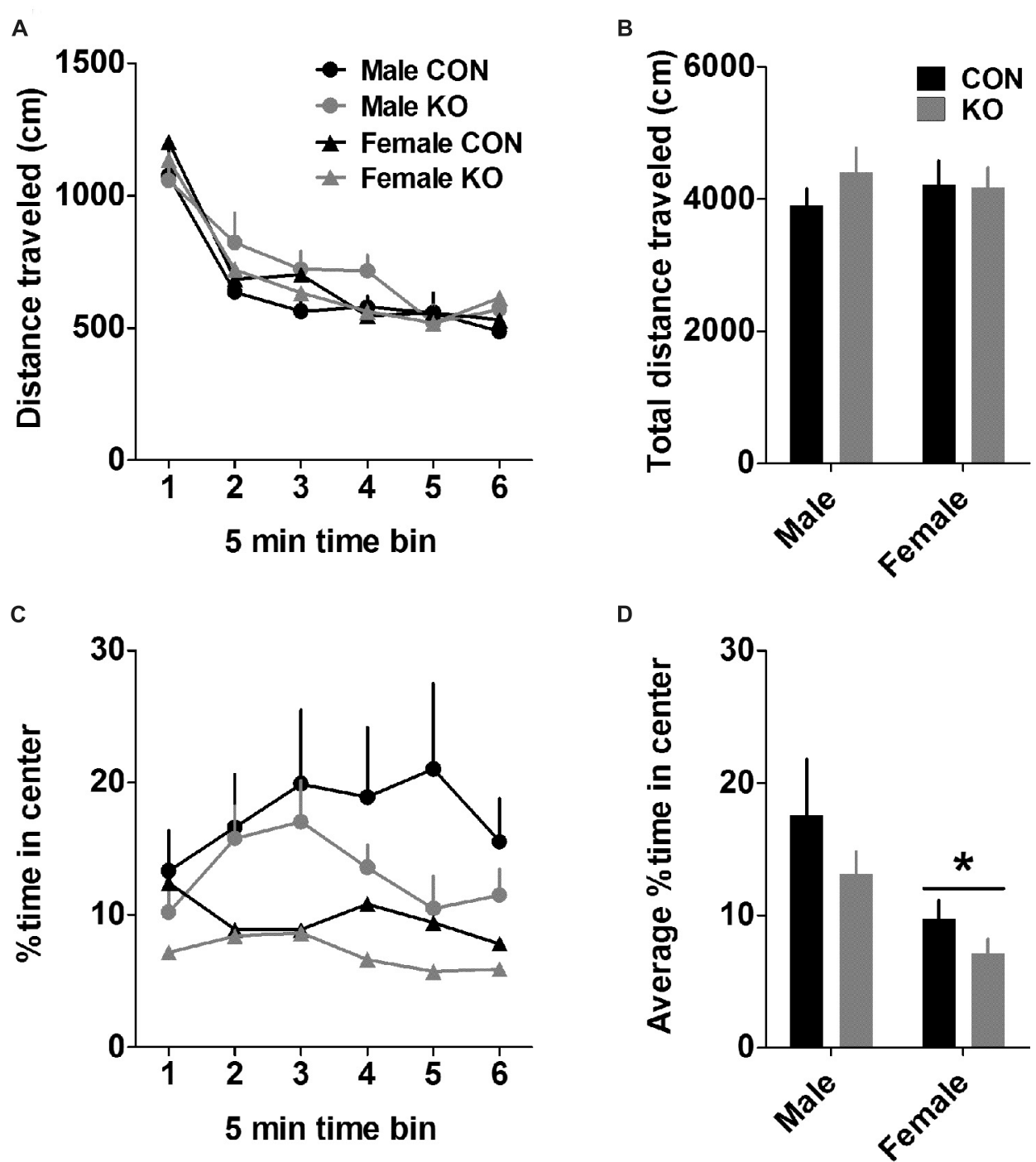

FIGURE 5 | Open field test. (A) Distance traveled across 5-min time bins in the open field. (B) There were no effects of sex or genotype on the total distance traveled in the open field. (C) Percent of time spent in the center of the open field across 5-min time bins. (D) Females spent less time in the center of the open field than males $\left({ }^{*} p<0.05\right)$, suggesting that females display higher basal anxiety than males but do not differ in basal locomotion ( $n$ 's: $\mathrm{CON}$ male $=11, \mathrm{KO}$ male $=10, \mathrm{CON}$ female $=11, \mathrm{KO}$ female $=10$ ). than females, while there were no effects of genotype or interactions between sex and genotype for any of these measures ( $p$ 's $>0.25)$.

\section{Forced swim test}

$\mathrm{KO}$ mice displayed greater depressive-like behavior in the forced swim test, demonstrated by a larger percent time immobile during the test in $\mathrm{KO}$ mice than controls [Figure $7 ; F(1,38)=7.04$, $p=0.013$ ] but no effect of sex or interaction ( $p$ 's $>0.60)$, suggesting that $\mathrm{Y} 2 \mathrm{Rs}$ on GABA neurons may play a role in regulating depressive-like behavior.

\section{Acoustic startle response}

There were no effects of sex, genotype, or their interaction in startle response to the acoustic stimulus ( $p$ 's $>0.15$; data not shown), suggesting that neither sex nor Y2R deletion from GABA neurons affects basal behavioral reactivity.

\section{Contextual and cued fear conditioning and memory}

Females learned to associate the context/cue to the foot shock more rapidly than males (Figures $\mathbf{8 A}, \mathbf{B}$ ), as demonstrated by a main effect of sex $[F(1,27)=4.71, p=0.039]$ but no effect of genotype or interaction between sex and genotype ( $p$ 's $>0.55$ ) on the average freezing during the second and third shock during conditioning. There were no effects found in the average freezing time during the context test the day after fear conditioning (Figures 8C,D; $p$ 's $>0.40$ ). On the cue test 1 day later, there was a trend toward a main effect of genotype [Figures 8E,F; $F(1,27)=3.61, p=0.068$ ] but no other effects $(p$ 's $>0.25)$. These results suggest that females have 

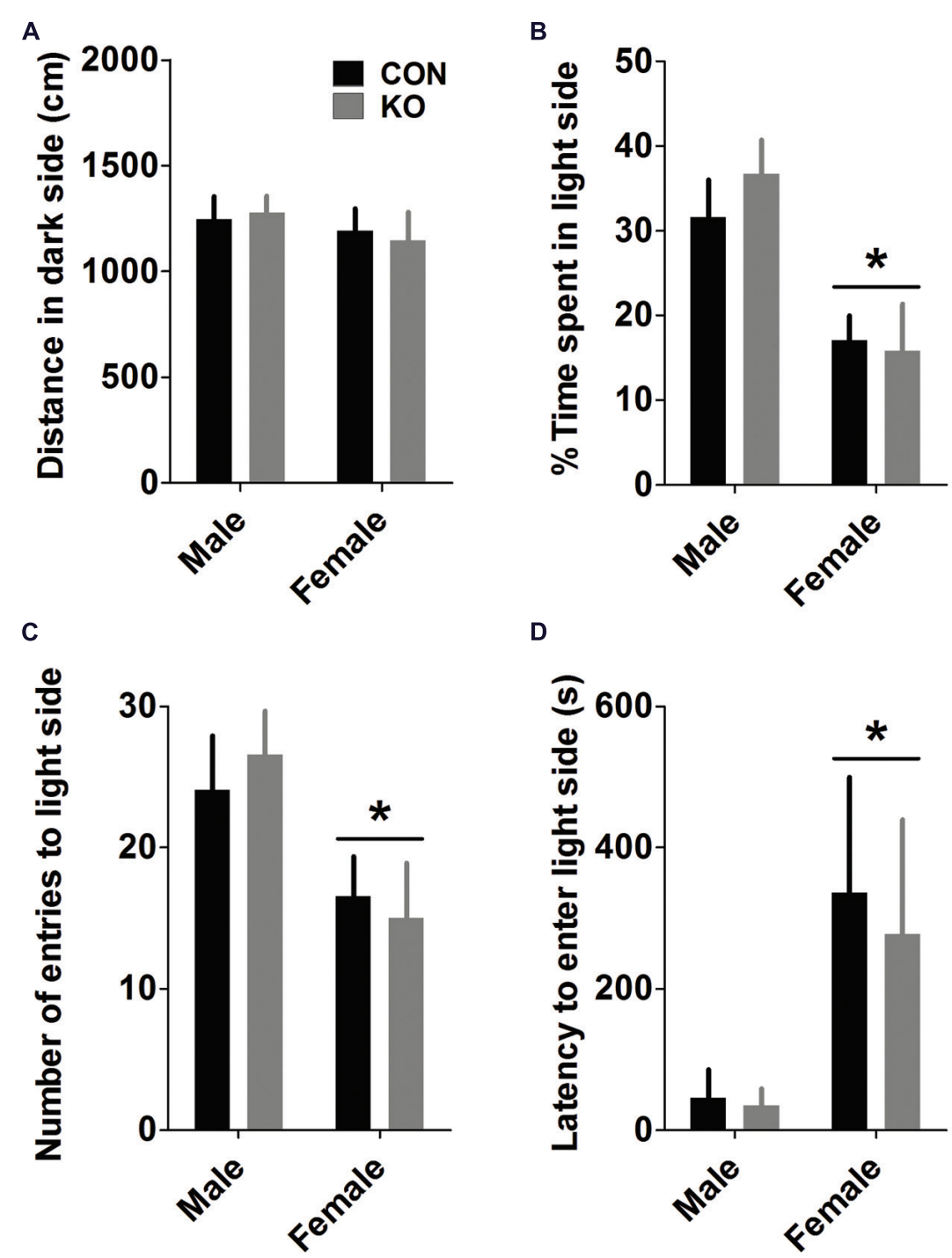

FIGURE 6 | Light/dark box. (A) Mice in all groups traveled similar distances in the dark side of the chamber (A). (B-D) Females spent less time in the light side of the chamber (B; * $\left.p^{\prime} \mathbf{s}<0.001\right)$, and made fewer entries into

faster fear learning and that Y2R deletion from GABA neurons modestly impairs cued fear memory but not contextual fear memory.

\section{Drinking in the dark procedure}

Analyses of ethanol consumption across the 4-day DID procedure showed that a sex difference emerged on Day 3 (Figure 9A), demonstrated by a main effect of $\operatorname{sex}[F(1,24)=7.25, p=0.013]$ but no effect of genotype or interaction ( $p$ 's $>0.80)$. This effect persisted on the binge test day (Figures 9A,B), shown by a main effect of $\operatorname{sex}[F(1,24)=19.56, p=0.0002]$ but no other effects ( $p$ 's $>0.50)$. An effect of sex on BEC after the binge ethanol session [Figure 9C; $F(1,25)=6.40$, $p=0.018]$, but no other effects $(p$ 's $>0.70)$, supports this finding.
D

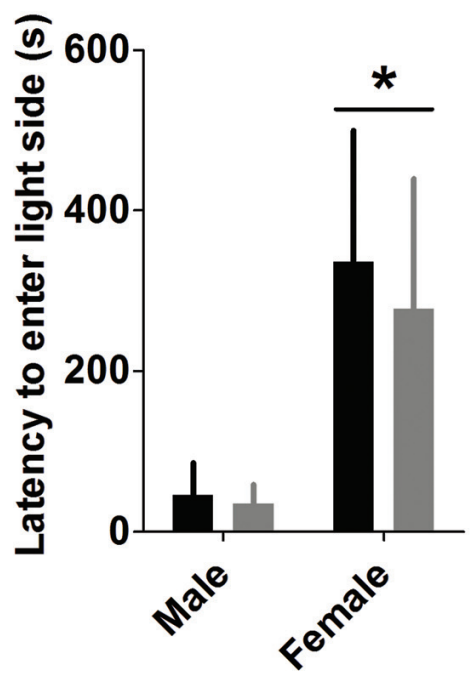

$\left(\mathbf{C} ;{ }^{*} p<0.001\right)$ and had a longer latency to first enter $\left(\mathbf{D} ;{ }^{*} p<0.05\right)$ the light side of the chamber than males, demonstrating greater anxiety-like behavior ( $n$ 's: $\mathrm{CON}$ male $=11, \mathrm{KO}$ male $=10, \mathrm{CON}$ female $=11, \mathrm{KO}$ female $=10$ ) .

\section{Sucrose and ethanol preference tests}

Analysis of total sucrose consumption during the 24-h sucrose preference test revealed a main effect of sex $[F(1,25)=15.89$, $p=0.0005]$ and an interaction between sex and genotype $[F(1,25)=6.31, p=0.019]$, but no main effect of genotype $(p>0.10)$. Post hoc $t$-tests with Bonferroni corrections showed that control females and $\mathrm{KO}$ males drank significantly more sucrose than control males [Figure 10A; $t(13)=5.14, p=0.0002$ and $(t(8)=2.87, p=0.021$, respectively], while there was no difference between female control and $\mathrm{KO}$ groups $(p>0.50)$. A similar analysis on water consumption revealed no effects (Figure 10B; $p$ 's $>0.05)$. In addition, analysis of sucrose preference revealed main effects of sex $[F(1,25)=7.14, p=0.013]$ and genotype $[F(1,25)=6.24, p=0.019]$, as well as an interaction between the two $[F(1,25)=11.55, p=0.002]$. Post hoc tests with Bonferroni 


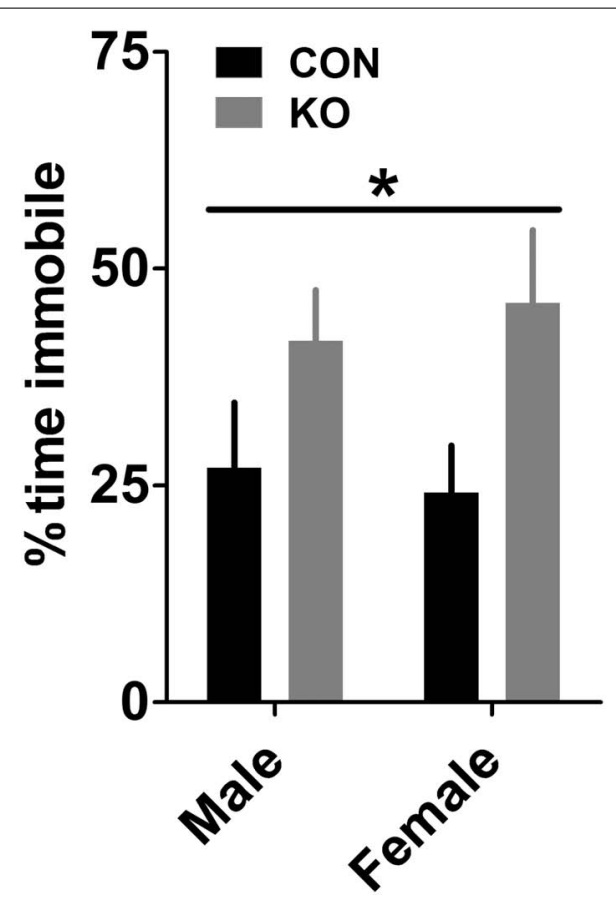

FIGURE 7 | Forced swim test. KO mice had increased immobility in the forced swim test compared to control mice $\left({ }^{*} p<0.05\right)$ but there was no effect of sex, suggesting that deletion of $Y 2 R$ from GABA neurons increases depressive-like behavior ( $n$ 's: $\mathrm{CON}$ male $=11, \mathrm{KO}$ male $=10$, $\mathrm{CON}$ female $=11, \mathrm{KO}$ female $=10$ ).

corrections were also similar to those for sucrose consumption, revealing increased sucrose preference in control females and $\mathrm{KO}$ males compared to control males [Figure 10C; $t(13)=4.68$, $p=0.0004$ and $t(8)=3.40, p=0.009$, respectively], with no difference between control and $\mathrm{KO}$ females $(p>0.40)$. These effects were primarily attributed to very low sucrose consumption and preference in control males.

We performed the same analyses for the ethanol preference test. Similar to results from the DID experiment, females consumed more ethanol than males, demonstrated by a main effect of sex [Figure 10D; $F(1,25)=6.39, p=0.018$ ] but no other effects $(p$ 's $>0.30)$. There was also a non-significant trend toward increased water intake in females (Figure 10E; $p=0.069$, other $p$ 's $>0.55)$. Together, these consumption levels led to no differences in ethanol preference (Figure 10F; $p$ 's $>0.45$ ).

\section{DISCUSSION}

In this study, we examined the effects of sex and deletion of the primary NPY receptor, Y2R, from GABA neurons on several measures of anxiety, depression, anhedonia, fear, and ethanol drinking behavior in mice on a C57BL/6J background. We found striking sex differences in these behaviors, with females displaying greater basal anxiety/fear and ethanol consumption in females than males, as observed in the light/dark box, open field test, fear conditioning, DID, and ethanol preference test. Many prior studies in rodents have also found that females display higher levels of basal anxiety, especially those using mice on a C57BL/6J background (Kennett et al., 1986; Johnston and File, 1991; Frye

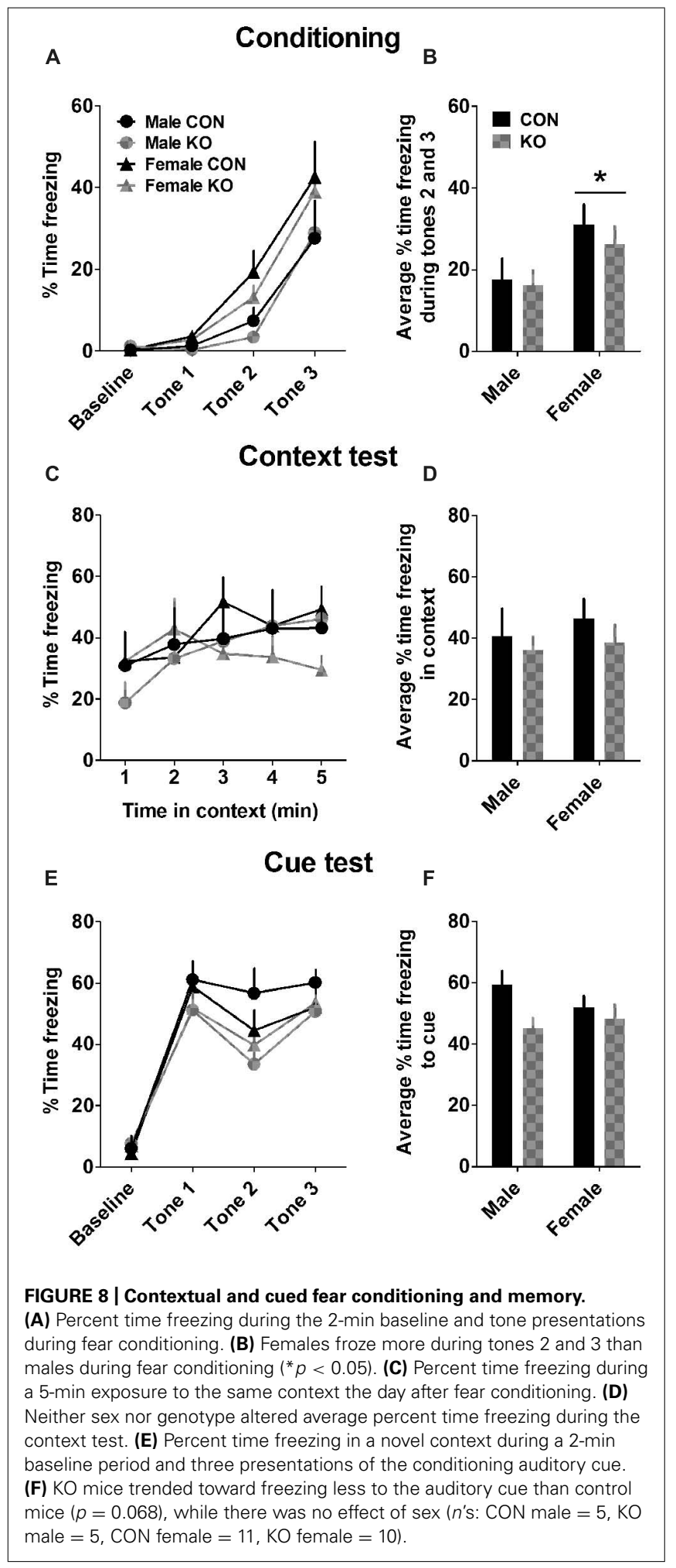

et al., 2000; Frye and Wawrzycki, 2003; Adamec et al., 2006; Dalla and Shors, 2009; Stack et al., 2010; ter Horst et al., 2012b). Notably, heightened stress reactivity, such as anxiety-like behavior on assays used in this study, and faster fear conditioning are two hallmark phenotypes in mouse models of generalized/sustained anxiety 


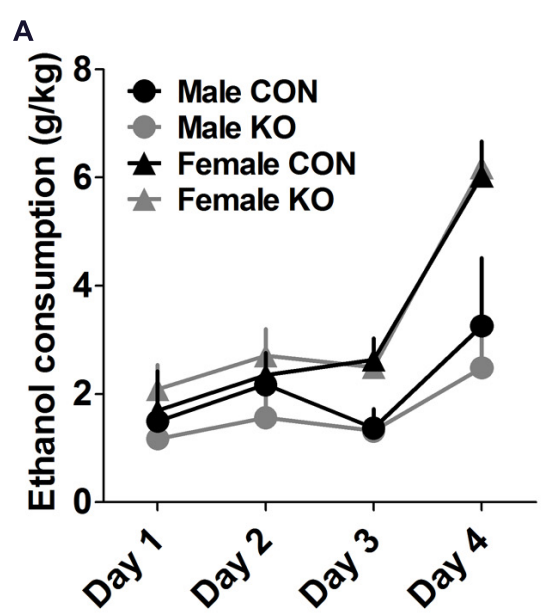

FIGURE 9 | Drinking in the Dark (DID) binge ethanol drinking test. (A) Ethanol consumption across the 4-day DID procedure, with $2 \mathrm{~h}$ of access to $20 \%$ ethanol during the first 3 days and $4 \mathrm{~h}$ of access on Day 4 (binge test
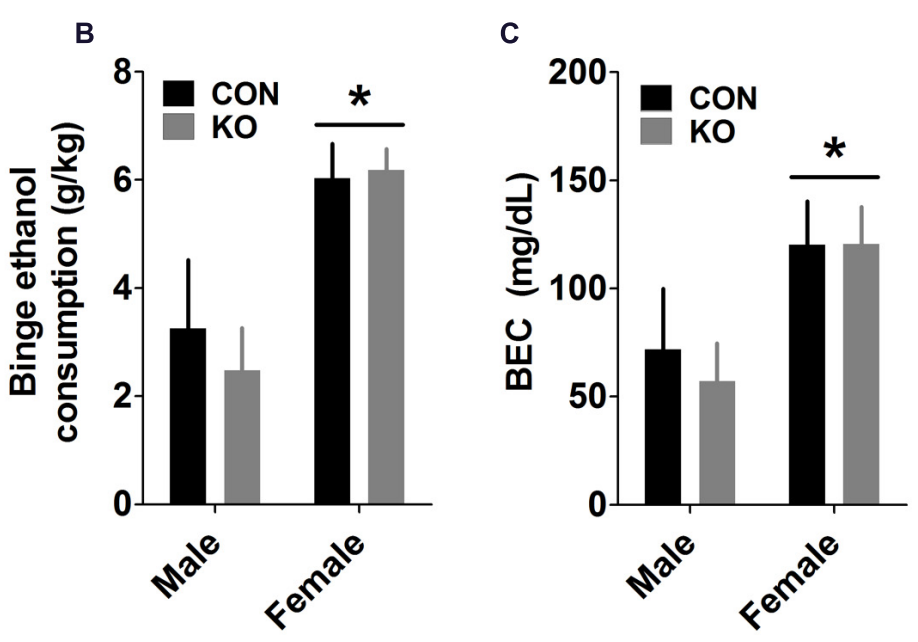

day). (B,C) Females drank significantly more than males on the binge test day (B) and had corresponding greater BECs $\left(\mathbf{C}\right.$; ${ }^{*} p$ 's $<0.05$; $n$ 's: CON male $=4$, $\mathrm{KO}$ male $=5, \mathrm{CON}$ female $=9$, $\mathrm{KO}$ female $=9$ )
(Charney et al., 1993; Cryan and Holmes, 2005; Brinks et al., 2008; ter Horst et al., 2012a,b; Andero et al., 2013; Cacciaglia et al., 2013; Griebel and Holmes, 2013). As women have a higher prevalence of these types of anxiety disorders than men, including generalized anxiety disorder and post-traumatic stress disorder (Kessler et al., 1994, 1995; Gater et al., 1998; Lewinsohn et al., 1998a,b; Bekker and van Mens-Verhulst, 2007), our data are consistent with the current human and mouse literature and suggest that mice on a C57BL/6J background may be good models for sex differences in anxiety in humans.

Interestingly, while we found that females displayed more anxiety-like behavior on the open field test and light/dark box than males, we found no sex differences in the elevated plus maze. While this is a standard assay for anxiety in rodents, there are several previous reports that results in the elevated plus maze were inconsistent with or less sensitive than other tests of anxiety (Johnston and File, 1991; Adamec et al., 2006). Further, evaluation of mouse behavior on a combined apparatus (elevated plus maze, open field test, and light/dark box) showed that mice spent a majority of their time in the elevated plus maze portion of the apparatus, suggesting that it is the least aversive of the three apparatuses (Fraser et al., 2010). Therefore, we and others may not have found a sex difference in anxiety on the elevated plus maze because it is not particularly anxiety-provoking.

As we observed here, other studies have also found greater binge ethanol consumption in female than male mice on a C57BL/6J background (Middaugh and Kelley, 1999; Middaugh et al., 1999; Hall et al., 2003; Rhodes et al., 2007; Agrawal et al., 2013; Melon et al., 2013). Interestingly, there is evidence suggesting that female C57 mice may drink more than males because they are less sensitive to the stimulant and sedative effects of ethanol, independent of BEC (Middaugh et al., 1999). This may be due to modulation of critical circuitry by ovarian hormones, as removal of these sex hormones via ovariectomy has been shown to decrease ethanol consumption in female C57BL/6 mice (Becker et al., 1985). In contrast, in humans, men binge drink more often and in greater excess than women. However, women have smaller gastric ethanol metabolism and less body water volume than men (Marshall et al., 1983; Baraona et al., 2001), leading to higher BECs and greater behavioral effects from the same dose of acute ethanol (Avant, 1990; Frezza et al., 1990; Ammon et al., 1996). As such, women are far more likely to become impaired, suffer greater organ and morphological brain changes, and develop comorbid medical conditions from ethanol consumption (Krasner et al., 1977; Eckardt et al., 1981; Urbano-Marquez et al., 1995; Key et al., 2006; Medina et al., 2008; Squeglia et al., 2012). Therefore, divergent sex differences in ethanol sensitivity in mice and humans may explain why sex differences in ethanol consumption are not consistent between these species.

Surprisingly, we found only one interaction between Y2R deletion and sex, which was observed in the sucrose preference test, a measure of anhedonia. Interestingly, this finding was due to the very low sucrose preference in control (VGAT-ires-Cre -/-, Y2R-floxed +/+) male mice, which may reflect a sex-specific background strain effect on anhedonia, hunger/thirst, or taste, as $\mathrm{KO}$ males and both female groups showed high sucrose consumption and preference over water. Given that ethanol and water consumption were not otherwise different between control and $\mathrm{KO}$ males, it is most likely that the hedonic value of sucrose is low in Y2R-floxed males. Interestingly, we did not observe any effect of $\mathrm{Y} 2 \mathrm{R}$ deletion from GABA neurons on anxiety in either sex. While this was somewhat surprising given the established role of $\mathrm{Y} 2 \mathrm{R}$ in these behaviors, we have previously demonstrated that the effects of stress on anxiety-like behavior and on Y2R modulation of GABAergic transmission in the BNST are background straindependent (Mozhui et al., 2010; Pleil et al., 2012). These studies demonstrated the stress-resilience of $\mathrm{C} 57 \mathrm{BL} / 6 \mathrm{~J}$ mice compared to stress-susceptible DBA/2J mice. Similarly, several other studies have found diverging behavioral phenotypes after complete, global Y2R knockout in mice depending on the background of the 
A

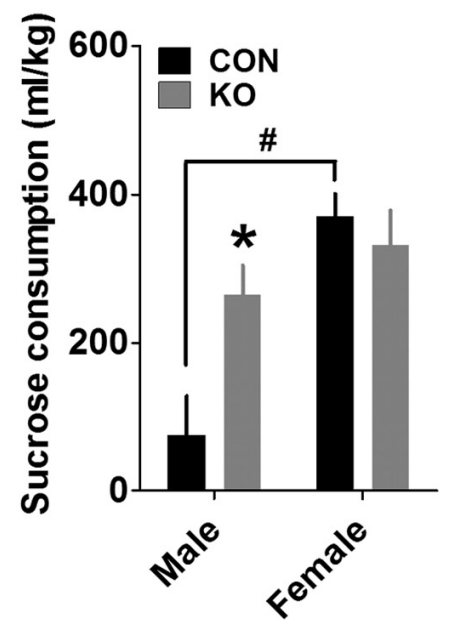

D

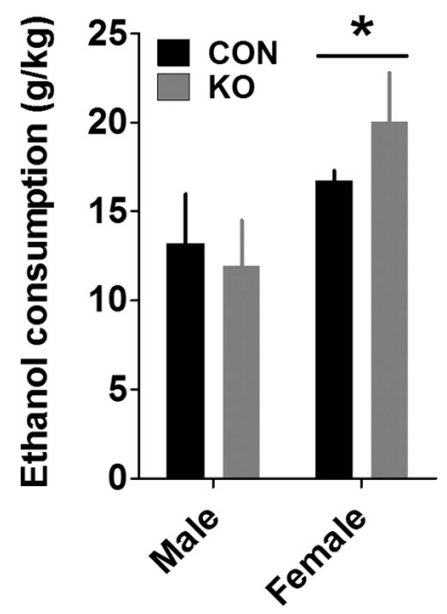

B

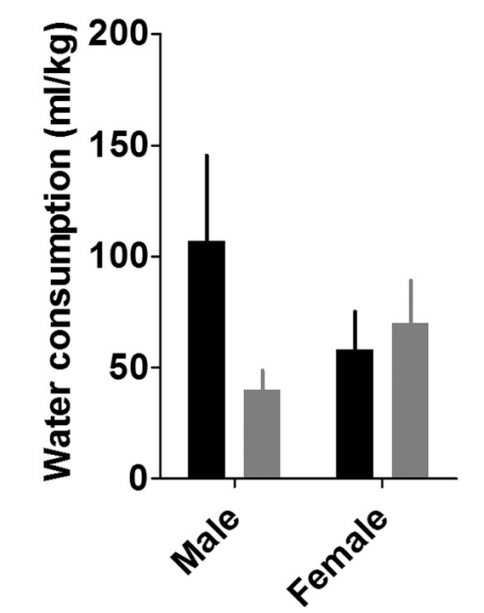

E

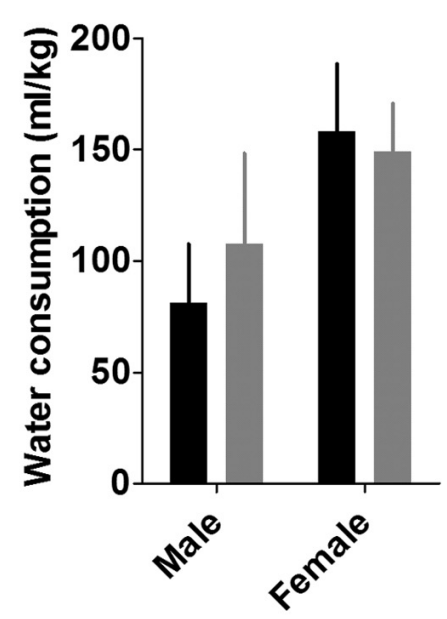

C

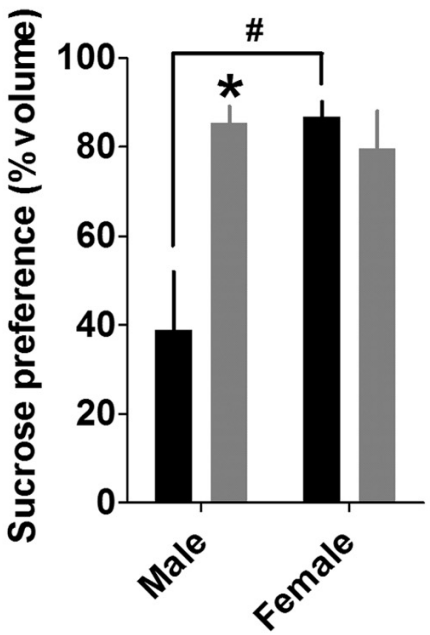

$\mathbf{F}$

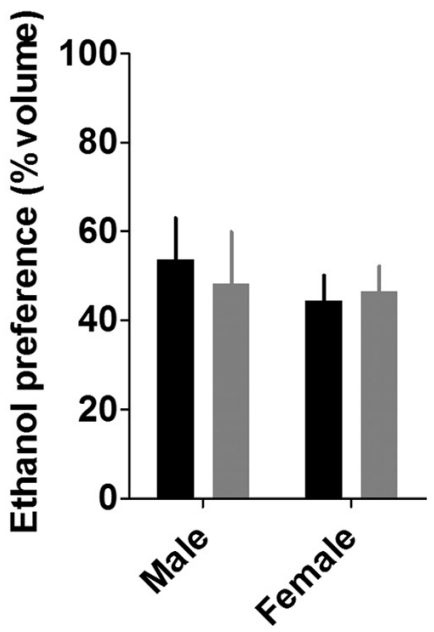

FIGURE 10 | Sucrose and ethanol preference tests. (A) Females drank more sucrose than males, and KO males drank more sucrose than control males during a 24 -h sucrose preference test ${ }^{*}$ indicates significantly different from control males with $p<0.05$; \#indicates significantly different from control males with $p<0.001)$. (B) There were no differences between groups in water consumption during the sucrose preference test. (C) Females displayed a greater sucrose preference than males, and KO males had a greater sucrose preference than control males (*indicates significantly different from control males with $p<0.01$; \#indicates significantly different from control males with $p<0.001$ ). (D-F) Females consumed more ethanol than males during a 24-h ethanol preference test $\left(\mathbf{D} ;{ }^{*} p<0.05\right)$ and trended toward consuming more water $(\mathbf{E} ; p=0.069)$, resulting in no differences in ethanol preference $(\mathbf{F} ; n$ 's: $\mathrm{CON}$ male $=5, \mathrm{KO}$ male $=5, \mathrm{CON}$ female $=10$, $\mathrm{KO}$ female $=9$ ). mice (Redrobe et al., 2003; Tschenett et al., 2003; Carvajal et al., 2006; Zambello et al., 2010). Here, we used mice on a C57BL/6J background because most of our and others' previous research on alcohol drinking behavior and mechanisms of NPY modulation of circuitry regulating emotional behaviors in mice has used this strain. Specifically, mice on a C57BL/6J strain drink ethanol readily, without the experimenter needing to induce ethanol drinking with a sucrose or MSG fade procedure as other strains require, such as DBA/2J. This allowed us to measure true basal levels of all behaviors in our study, including ethanol drinking. However, we may have observed effects of Y2R deletion from GABA neurons on the behaviors measured had mice been on a more stress-susceptible background, such as DBA/2J. In addition, Y2R-mediated effects on GABAergic transmission and emotional behaviors may emerge after exposure to chronic stress that elicits tonic engagement of the endogenous NPY system.

Our results on the role of Y2R on GABA neurons in depressivelike and anxiety-like behavior are in contrast to previous reports examining site-specific actions of Y2R or manipulation of Y2R in a cell-type non-specific manner. A previous report found that conditional deletion of all Y2R from the CeA decreased depressive-like behavior in the tail suspension test (Tasan et al., 2010). We found that global deletion of Y2R from all GABA neurons increased depressive-like behavior in the forced swim test. Together, these results suggest that (1) the depressive-like effects of $\mathrm{Y} 2 \mathrm{R}$ in the CeA are due to modulation of non-GABAergic cell types and (2) Y2R actions on GABA transmission in the CeA, or more broadly throughout the brain, may counteract its actions 
at non-GABAergic synapses. This is not very surprising given the complex role of $\mathrm{Y} 2 \mathrm{R}$ as an autoreceptor and a heteroceptor for many other neurotransmitters implicated in anxiety and depression behaviors. For example, Y2R acts as a heteroceptor on glutamatergic neurons to decrease glutamate release, and it is colocalized with norepinephrine and dopamine terminals (Silva et al., 2001, 2005; Adewale et al., 2007; Nadler et al., 2007; Shoblock et al., 2010; Zambello et al., 2010; Ledri et al., 2011; Stanic et al., 2011). As $\mathrm{Y} 2 \mathrm{R}$ is able to decrease the release of both GABA and glutamate, manipulation of one of these functions versus manipulation of both functions would likely result in different behavioral effects. This interpretation is also consistent with our finding that Y2R deletion from GABA neurons did not alter anxiety-like behavior. Several studies have found that complete and global Y2R deletion, systemic $\mathrm{Y} 2 \mathrm{R}$ antagonism, or $\mathrm{Y} 2 \mathrm{R}$ antagonism in the CeA decrease anxiety-like behavior (Redrobe et al., 2003; Tschenett et al., 2003; Carvajal et al., 2006; Kallupi et al., 2013) or have no effect (Zambello et al., 2010), suggesting that, together with our findings, the anxiogenic effects of Y2R activation in the CeA or more broadly in the brain are due to its role at non-GABAergic terminals.

Although we have previously demonstrated that Y2R modulates GABAergic transmission reliably across neurons in the BNST (Kash and Winder, 2006; Pleil et al., 2012), deletion of $\mathrm{Y} 2 \mathrm{R}$ from GABA neurons in this study did not result in less immunofluorescence for Y2R protein in the BNST. However, we functionally confirmed Y2R deletion from GABA neurons in the BNST using slice electrophysiology. As Y2R appears to be ubiquitously expressed throughout the BNST, and deletion of Y2R only from GABA neurons was not be detectable with immunofluorescence, our data suggest that many different types of neurons play host to presynaptic Y2R in the BNST. Future studies combining cell-type and site-specific approaches will help refine our understanding of the loci of Y2R in critical limbic regions and its role in affective and reward-related behaviors.

\section{AUTHOR CONTRIBUTIONS}

Nora M. McCall conducted anxiety-like behavioral assays, maintained breeding colonies, performed immunohistochemical procedures, and helped write the manuscript. Gretchen M. Sprow conducted ethanol and sucrose drinking tests. Eric Delpire generated the Y2R-floxed mice. Todd E. Thiele helped design the study and oversaw ethanol and sucrose drinking tests. Thomas L. Kash designed the study and oversaw anxietylike behavioral experiments. Kristen E. Pleil helped design the study, performed electrophysiological experiments, analyzed the data, and wrote the manuscript. All authors edited the manuscript.

\section{ACKNOWLEDGMENTS}

This work was supported by the following grants: AA022048, AA013573, and AA015148 to Todd E. Thiele, AA021043 to Kristen E. Pleil, AA020911 to Thomas L. Kash, and AA013514 to Eric Delpire. Sheryl Moy, Lorinda Baker, and Randy Nonneman assisted with the use of equipment at the UNC Mouse Behavioral Phenotyping Core.

\section{REFERENCES}

Adamec, R., Head, D., Blundell, J., Burton, P., and Berton, O. (2006). Lasting anxiogenic effects of feline predator stress in mice: sex differences in vulnerability to stress and predicting severity of anxiogenic response from the stress experience. Physiol. Behav. 88, 12-29. doi: 10.1016/j.physbeh.2006. 03.005

Adewale, A. S., Macarthur, H., and Westfall, T. C. (2007). Neuropeptide Y-induced enhancement of the evoked release of newly synthesized dopamine in rat striatum: mediation by Y2 receptors. Neuropharmacology 52, 1396-1402. doi: 10.1016/j.neuropharm.2007.01.018

Agrawal, R. G., Owen, J. A., Levin, P. S., Hewetson, A., Berman, A. E., Franklin, S. R., et al. (2013). Bioinformatics analyses reveal age-specific neuroimmune modulation as a target for treatment of high ethanol drinking. Alcohol. Clin. Exp. Res. doi: 10.1111/acer.12288 [Epub ahead of print].

Ammon, E., Schafer, C., Hofmann, U., and Klotz, U. (1996). Disposition and first-pass metabolism of ethanol in humans: is it gastric or hepatic and does it depend on gender? Clin. Pharmacol. Ther. 59, 503-513. doi: 10.1016/S00099236(96)90178-2

Andero, R., Brothers, S. P., Jovanovic, T., Chen, Y. T., Salah-Uddin, H., Cameron, M., et al. (2013). Amygdala-dependent fear is regulated by Oprll in mice and humans with PTSD. Sci. Transl. Med. 5, 188ra173. doi: 10.1126/scitranslmed.3005656

Avant, L. L. (1990). Alcohol impairs visual presence/absence detection more for females than for males. Percept. Psychophys. 48, 285-290. doi: 10.3758/BF03211531

Bacchi, F., Mathe, A. A., Jimenez, P., Stasi, L., Arban, R., Gerrard, P., et al. (2006). Anxiolytic-like effect of the selective neuropeptide Y Y2 receptor antagonist BIIE0246 in the elevated plus-maze. Peptides 27, 3202-3207. doi: 10.1016/j.peptides.2006.07.020

Bannon, A. W., Seda, J., Carmouche, M., Francis, J. M., Norman, M. H., Karbon, B., et al. (2000). Behavioral characterization of neuropeptide Y knockout mice. Brain Res. 868, 79-87. doi: 10.1016/S0006-8993(00)02285-X

Baraona, E., Abittan, C. S., Dohmen, K., Moretti, M., Pozzato, G., Chayes, Z. W., et al. (2001). Gender differences in pharmacokinetics of alcohol. Alcohol. Clin. Exp. Res. 25, 502-507. doi: 10.1111/j.1530-0277.2001.tb02242.x

Becker, H. C., Anton, R. F., De Trana, C., and Randall, C. L. (1985). Sensitivity to ethanol in female mice: effects of ovariectomy and strain. Life Sci. 37, 1293-1300. doi: 10.1016/0024-3205(85)90244-9

Bekker, M. H., and van Mens-Verhulst, J. (2007). Anxiety disorders: sex differences in prevalence, degree, and background, but gender-neutral treatment. Gend. Med. 4, S178-S193. doi: 10.1016/S1550-8579(07)80057-X

Bertocchi, I., Oberto, A., Longo, A., Mele, P., Sabetta, M., Bartolomucci, A., et al. (2011). Regulatory functions of limbic Y1 receptors in body weight and anxiety uncovered by conditional knockout and maternal care. Proc. Natl. Acad. Sci. U.S.A. 108, 19395-19400. doi: 10.1073/pnas.1109468108

Brinks, V., de Kloet, E. R., and Oitzl, M. S. (2008). Strain specific fear behaviour and glucocorticoid response to aversive events: modelling PTSD in mice. Prog. Brain Res. 167, 257-261. doi: 10.1016/S0079-6123(07)67019-8

Brunssen, S. H., Moy, S. S., Toews, A. D., McPherson, C. A., and Harry, G. J. (2013). Interleukin-6 (IL-6) receptor/IL-6 fusion protein (Hyper IL-6) effects on the neonatal mouse brain: possible role for IL- 6 trans-signaling in brain development and functional neurobehavioral outcomes. Brain Behav. Immun. 27, 42-53. doi: 10.1016/j.bbi.2012.08.017

Cacciaglia, R., Krause-Utz, A., Vogt, M. A., Schmahl, C., Flor, H., and Gass, P. (2013). Voluntary exercise does not ameliorate context memory and hyperarousal in a mouse model for post-traumatic stress disorder (PTSD). World J. Biol. Psychiatry 14, 403-409. doi: 10.3109/15622975.2011.583270

Carvajal, C., Dumont, Y., Herzog, H., and Quirion, R. (2006). Emotional behavior in aged neuropeptide Y (NPY) Y2 knockout mice. J. Mol. Neurosci. 28, 239-245. doi: 10.1385/JMN:28:3:239

Charney, D. S., Deutch, A. Y., Krystal, J. H., Southwick, S. M., and Davis, M. (1993). Psychobiologic mechanisms of posttraumatic stress disorder. Arch. Gen. Psychiatry 50, 295-305. doi: 10.1001/archpsyc.1993.01820160064008

Chee, M. J., Myers, M. G. Jr., Price, C. J., and Colmers, W. F. (2010). Neuropeptide Y suppresses anorexigenic output from the ventromedial nucleus of the hypothalamus. J. Neurosci. 30, 3380-3390. doi: 10.1523/JNEUROSCI.4031-09.2010

Cryan, J. F., and Holmes, A. (2005). The ascent of mouse: advances in modelling human depression and anxiety. Nat. Rev. Drug Discov. 4, 775-790. doi: $10.1038 / \operatorname{nrd} 1825$ 
Dalla, C., and Shors, T. J. (2009). Sex differences in learning processes of classical and operant conditioning. Physiol. Behav. 97, 229-238. doi: 10.1016/j.physbeh.2009.02.035

Eckardt, M. J., Harford, T. C., Kaelber, C. T., Parker, E. S., Rosenthal, L. S., Ryback, R. S., et al. (1981). Health hazards associated with alcohol consumption. JAMA 246, 648-666. doi: 10.1001/jama.1981.03320060050022

Fendt, M., Burki, H., Imobersteg, S., Lingenhohl, K., McAllister, K. H., Orain, D., et al. (2009). Fear-reducing effects of intra-amygdala neuropeptide $\mathrm{Y}$ infusion in animal models of conditioned fear: an NPY Y1 receptor independent effect. Psychopharmacology (Berl.) 206, 291-301. doi: 10.1007/s00213-009-1610-8

Fraser, L. M., Brown, R. E., Hussin, A., Fontana, M., Whittaker, A., O'Leary, T. P., et al. (2010). Measuring anxiety- and locomotion-related behaviours in mice: a new way of using old tests. Psychopharmacology (Berl.) 211, 99-112. doi: 10.1007/s00213-010-1873-0

Frezza, M., di Padova, C., Pozzato, G., Terpin, M., Baraona, E., and Lieber, C. S. (1990). High blood alcohol levels in women. The role of decreased gastric alcohol dehydrogenase activity and first-pass metabolism. N. Engl. J. Med. 322, 95-99. doi: 10.1056/NEJM199001113220205

Frye, C. A., and Wawrzycki, J. (2003). Effect of prenatal stress and gonadal hormone condition on depressive behaviors of female and male rats. Horm. Behav. 44, 319-326. doi: 10.1016/S0018-506X(03)00159-4

Frye, C. A., Petralia, S. M., and Rhodes, M. E. (2000). Estrous cycle and sex differences in performance on anxiety tasks coincide with increases in hippocampal progesterone and 3alpha, 5alpha-THP. Pharmacol. Biochem. Behav. 67, 587-596. doi: 10.1016/S0091-3057(00)00392-0

Gater, R., Tansella, M., Korten, A., Tiemens, B. G., Mavreas, V. G., and Olatawura, M. O. (1998). Sex differences in the prevalence and detection of depressive and anxiety disorders in general health care settings: report from the World Health Organization Collaborative Study on Psychological Problems in General Health Care. Arch. Gen. Psychiatry 55, 405-413. doi: 10.1001/archpsyc.55.5.405

Gilpin, N. W., Misra, K., Herman, M. A., Cruz, M. T., Koob, G. F., and Roberto, M. (2011). Neuropeptide Y opposes alcohol effects on gamma-aminobutyric acid release in amygdala and blocks the transition to alcohol dependence. Biol. Psychiatry 69, 1091-1099. doi: 10.1016/j.biopsych.2011.02.004

Griebel, G., and Holmes, A. (2013). 50 years of hurdles and hope in anxiolytic drug discovery. Nat. Rev. Drug Discov. 12, 667-687. doi: 10.1038/nrd4075

Hall, F. S., Sora, I., and Uhl, G. R. (2003). Sex-dependent modulation of ethanol consumption in vesicular monoamine transporter 2 (VMAT2) and dopamine transporter (DAT) knockout mice. Neuropsychopharmacology 28, 620-628. doi: 10.1038/sj.npp.1300070

Heilig, M., Soderpalm, B., Engel, J. A., and Widerlov, E. (1989). Centrally administered neuropeptide Y (NPY) produces anxiolytic-like effects in animal anxiety models. Psychopharmacology (Berl.) 98, 524-529. doi: 10.1007/BF00441953

Huang, A. C., Shyu, B. C., Hsiao, S., Chen, T. C., and He, A. B. (2013). Neural substrates of fear conditioning, extinction, and spontaneous recovery in passive avoidance learning: a c-fos study in rats. Behav. Brain Res. 237, 23-31. doi: 10.1016/j.bbr.2012.09.024

Johnston, A. L., and File, S. E. (1991). Sex differences in animal tests of anxiety. Physiol. Behav. 49, 245-250. doi: 10.1016/0031-9384(91)90039-Q

Kallupi, M., Vendruscolo, L. F., Carmichael, C. Y., George, O., Koob, G. F., and Gilpin, N. W. (2013). Neuropeptide Y Y R blockade in the central amygdala reduces anxiety-like behavior but not alcohol drinking in alcohol-dependent rats. Addict. Biol. doi: 10.1111/adb.12059 [Epub ahead of print].

Karlsson, R. M., Choe, J. S., Cameron, H. A., Thorsell, A., Crawley, J. N., Holmes, A., et al. (2008). The neuropeptide Y Y1 receptor subtype is necessary for the anxiolytic-like effects of neuropeptide $\mathrm{Y}$, but not the antidepressant-like effects of fluoxetine, in mice. Psychopharmacology (Berl.) 195, 547-557. doi: 10.1007/s00213-007-0945-2

Kash, T. L., and Winder, D. G. (2006). Neuropeptide Y and corticotropinreleasing factor bi-directionally modulate inhibitory synaptic transmission in the bed nucleus of the stria terminalis. Neuropharmacology 51, 1013-1022. doi: 10.1016/j.neuropharm.2006.06.011

Kask, A., Rago, L., and Harro, J. (1998). Anxiolytic-like effect of neuropeptide Y (NPY) and NPY13-36 microinjected into vicinity of locus coeruleus in rats. Brain Res. 788, 345-348. doi: 10.1016/S0006-8993(98)00076-6

Kennett, G. A., Curzon, G., Hunt, A., and Patel, A. J. (1986). Immobilization decreases amino acid concentrations in plasma but maintains or increases them in brain. J. Neurochem. 46, 208-212. doi: 10.1111/j.1471-4159.1986.tb12947.x
Kessler, R. C., McGonagle, K. A., Zhao, S., Nelson, C. B., Hughes, M., Eshleman, S., et al. (1994). Lifetime and 12-month prevalence of DSM-III-R psychiatric disorders in the United States. Results from the National Comorbidity Survey. Arch. Gen. Psychiatry 51, 8-19. doi: 10.1001/archpsyc.1994.03950010008002

Kessler, R. C., Sonnega, A., Bromet, E., Hughes, M., and Nelson, C. B. (1995). Posttraumatic stress disorder in the National Comorbidity Survey. Arch. Gen. Psychiatry 52, 1048-1060. doi: 10.1001/archpsyc.1995.03950240066012

Key, J., Hodgson, S., Omar, R. Z., Jensen, T. K., Thompson, S. G., Boobis, A. R. et al. (2006). Meta-analysis of studies of alcohol and breast cancer with consideration of the methodological issues. Cancer Causes Control 17, 759-770. doi: 10.1007/s10552-006-0011-0

Krasner, N., Davis, M., Portmann, B., and Williams, R. (1977). Changing pattern of alcoholic liver disease in Great Britain: relation to sex and signs of autoimmunity. Br. Med. J. 1, 1497-1500. doi: 10.1136/bmj.1.6075.1497

Ledri, M., Sorensen, A. T., Erdelyi, F., Szabo, G., and Kokaia, M. (2011). Tuning afferent synapses of hippocampal interneurons by neuropeptide Y. Hippocampus 21, 198-211. doi: 10.1002/hipo.20740

Leret, M. L., Molina-Holgado, F., and Gonzalez, M. I. (1994). The effect of perinatal exposure to estrogens on the sexually dimorphic response to novelty. Physiol. Behav. 55, 371-373. doi: 10.1016/0031-9384(94)90148-1

Lewinsohn, P. M., Rohde, P., and Seeley, J. R. (1998a). Major depressive disorder in older adolescents: prevalence, risk factors, and clinical implications. Clin. Psychol. Rev. 18, 765-794. doi: 10.1016/S0272-7358(98)00010-5

Lewinsohn, P. M., Gotlib, I. H., Lewinsohn, M., Seeley, J. R., and Allen, N. B. (1998b). Gender differences in anxiety disorders and anxiety symptoms in adolescents. $J$ Abnorm. Psychol. 107, 109-117. doi: 10.1037/0021-843X.107.1.109

Li, C., Pleil, K. E., Stamatakis, A. M., Busan, S., Vong, L., Lowell, B. B., et al. (2012). Presynaptic inhibition of gamma-aminobutyric acid release in the bed nucleus of the stria terminalis by kappa opioid receptor signaling. Biol. Psychiatry 71, 725-732. doi: 10.1016/j.biopsych.2011.11.015

Lindell, S. G., Schwandt, M. L., Sun, H., Sparenborg, J. D., Bjork, K., Kasckow, J. W., et al. (2010). Functional NPY variation as a factor in stress resilience and alcohol consumption in rhesus macaques. Arch. Gen. Psychiatry 67, 423-431. doi: 10.1001/archgenpsychiatry.2010.23

Lowery-Gionta, E. G., Navarro, M., Li, C., Pleil, K. E., Rinker, J. A., Cox, B. R., et al. (2012). Corticotropin releasing factor signaling in the central amygdala is recruited during binge-like ethanol consumption in C57BL/6J mice. J. Neurosci. 32, 3405-3413. doi: 10.1523/JNEUROSCI.6256-11.2012

Marshall, A. W., Kingstone, D., Boss, M., and Morgan, M. Y. (1983). Ethanol elimination in males and females: relationship to menstrual cycle and body composition. Hepatology 3, 701-706. doi: 10.1002/hep.1840030513

Medina, K. L., McQueeny, T., Nagel, B. J., Hanson, K. L., Schweinsburg, A. D., and Tapert, S. F. (2008). Prefrontal cortex volumes in adolescents with alcohol use disorders: unique gender effects. Alcohol. Clin. Exp. Res. 32, 386-394. doi: 10.1111/j.1530-0277.2007.00602.x

Melon, L. C., Wray, K. N., Moore, E. M., and Boehm, S. L. II (2013). Sex and age differences in heavy binge drinking and its effects on alcohol responsivity following abstinence. Pharmacol. Biochem. Behav. 104, 177-187. doi: 10.1016/j.pbb.2013.01.005

Middaugh, L. D., and Kelley, B. M. (1999). Operant ethanol reward in C57BL/6 mice: influence of gender and procedural variables. Alcohol 17, 185-194. doi: 10.1016/S0741-8329(98)00056-1

Middaugh, L. D., Kelley, B. M., Bandy, A. L., and McGroarty, K. K. (1999). Ethanol consumption by C57BL/6 mice: influence of gender and procedural variables. Alcohol 17, 175-183. doi: 10.1016/S0741-8329(98)00055-X

Mozhui, K., Karlsson, R. M., Kash, T. L., Ihne, J., Norcross, M., Patel, S., et al. (2010). Strain differences in stress responsivity are associated with divergent amygdala gene expression and glutamate-mediated neuronal excitability. J. Neurosci. 30, 5357-5367. doi: 10.1523/JNEUROSCI.5017-09.2010

Nadler, J. V., Tu, B., Timofeeva, O., Jiao, Y., and Herzog, H. (2007). Neuropeptide $\mathrm{Y}$ in the recurrent mossy fiber pathway. Peptides 28, 357-364. doi: 10.1016/j.peptides.2006.07.026

Ohrmann, P., Pedersen, A., Braun, M., Bauer, J., Kugel, H., Kersting, A., et al. (2010). Effect of gender on processing threat-related stimuli in patients with panic disorder: sex does matter. Depress. Anxiety 27, 1034-1043. doi: 10.1002/da.20721

Parker, R. M., and Herzog, H. (1999). Regional distribution of Y-receptor subtype mRNAs in rat brain. Eur. J. Neurosci. 11, 1431-1448. doi: 10.1046/j.14609568.1999.00553.x 
Pleil, K. E., Lopez, A., McCall, N., Jijon, A. M., Bravo, J. P., and Kash, T. L. (2012). Chronic stress alters neuropeptide $\mathrm{Y}$ signaling in the bed nucleus of the stria terminalis in DBA/2J but not C57BL/6J mice. Neuropharmacology 62, 1777-1786. doi: 10.1016/j.neuropharm.2011.12.002

Redrobe, J. P., Dumont, Y., Herzog, H., and Quirion, R. (2003). Neuropeptide Y (NPY) Y2 receptors mediate behaviour in two animal models of anxiety: evidence from Y2 receptor knockout mice. Behav. Brain Res. 141, 251-255. doi: 10.1016/S0166-4328(02)00374-1

Rhodes, J. S., Ford, M. M., Yu, C. H., Brown, L. L., Finn, D. A., Garland, T. Jr., et al. (2007). Mouse inbred strain differences in ethanol drinking to intoxication. Genes Brain Behav. 6, 1-18. doi: 10.1111/j.1601-183X.2006.00210.x

Rodgers, R. J., and Cole, J. C. (1993). Influence of social isolation, gender, strain, and prior novelty on plus-maze behaviour in mice. Physiol. Behav. 54, 729-736. doi: 10.1016/0031-9384(93)90084-S

Schroeder, J. P., Olive, F., Koenig, H., and Hodge, C. W. (2003). Intra-amygdala infusion of the NPY Y1 receptor antagonist BIBP 3226 attenuates operant ethanol self-administration. Alcohol. Clin. Exp. Res. 27, 1884-1891. doi: 10.1097/01.ALC.0000098875.95923.69

Shoblock, J. R., Welty, N., Nepomuceno, D., Lord, B., Aluisio, L., Fraser, I., etal. (2010). In vitro and in vivo characterization of JNJ31020028 (N-(4-\{4-[2-(diethylamino)-2-oxo-1-phenylethyl]piperazin-1-yl\}-3fluorophenyl)-2- pyridin-3-ylbenzamide), a selective brain penetrant small molecule antagonist of the neuropeptide Y Y(2) receptor. Psychopharmacology (Berl.) 208, 265-277. doi: 10.1007/s00213-009-1726-X

Silva, A. P., Carvalho, A. P., Carvalho, C. M., and Malva, J. O. (2001). Modulation of intracellular calcium changes and glutamate release by neuropeptide $\mathrm{Y} 1$ and Y2 receptors in the rat hippocampus: differential effects in CA1, CA3 and dentate gyrus. J. Neurochem. 79, 286-296. doi: 10.1046/j.1471-4159.2001. 00560.x

Silva, A. P., Xapelli, S., Grouzmann, E., and Cavadas, C. (2005). The putative neuroprotective role of neuropeptide $\mathrm{Y}$ in the central nervous system. Curr. Drug Targets CNS Neurol. Disord. 4, 331-347. doi: 10.2174/1568007054546153

Sparrow, A. M., Lowery-Gionta, E. G., Pleil, K. E., Li, C., Sprow, G. M., Cox, B. R., et al. (2012). Central neuropeptide $Y$ modulates binge-like ethanol drinking in C57BL/6J mice via Y1 and Y2 receptors. Neuropsychopharmacology 37, 1409-1421. doi: 10.1038/npp.2011.327

Sparta, D. R., Sparrow, A. M., Lowery, E. G., Fee, J. R., Knapp, D. J., and Thiele, T. E. (2008). Blockade of the corticotropin releasing factor type 1 receptor attenuates elevated ethanol drinking associated with drinking in the dark procedures. Alcohol. Clin. Exp. Res. 32, 259-265. doi: 10.1111/j.1530-0277.2007. 00575.x

Squeglia, L. M., Sorg, S. F., Schweinsburg, A. D., Wetherill, R. R., Pulido, C., and Tapert, S. F. (2012). Binge drinking differentially affects adolescent male and female brain morphometry. Psychopharmacology (Berl.) 220, 529-539. doi: 10.1007/s00213-011-2500-4

Stack, A., Carrier, N., Dietz, D., Hollis, F., Sorenson, J., and Kabbaj, M. (2010). Sex differences in social interaction in rats: role of the immediate-early gene zif 268 . Neuropsychopharmacology 35, 570-580. doi: 10.1038/npp.2009.163

Stanic, D., Mulder, J., Watanabe, M., and Hokfelt, T. (2011). Characterization of NPY Y2 receptor protein expression in the mouse brain. II. Coexistence with NPY, the Y1 receptor, and other neurotransmitter-related molecules. J. Comp. Neurol. 519, 1219-1257. doi: 10.1002/cne.22608

Tasan, R. O., Nguyen, N. K., Weger, S., Sartori, S. B., Singewald, N., Heilbronn, R., etal. (2010). The central and basolateral amygdala are critical sites of neuropeptide $\mathrm{Y} / \mathrm{Y} 2$ receptor-mediated regulation of anxiety and depression. J. Neurosci. 30, 6282-6290. doi: 10.1523/JNEUROSCI.043010.2010 ter Horst, J. P., de Kloet, E. R., Schachinger, H., and Oitzl, M. S. (2012a). Relevance of stress and female sex hormones for emotion and cognition. Cell. Mol. Neurobiol 32, 725-735. doi: 10.1007/s10571-011-9774-2

ter Horst, J. P., Carobrez, A. P., van der Mark, M. H., de Kloet, E. R., and Oitzl, M. S. (2012b). Sex differences in fear memory and extinction of mice with forebrainspecific disruption of the mineralocorticoid receptor. Eur. J. Neurosci. 36, 3096 3102. doi: 10.1111/j.1460-9568.2012.08237.x

Thiele, T. E., Naveilhan, P., and Ernfors, P. (2004). Assessment of ethanol consumption and water drinking by NPY Y(2) receptor knockout mice. Peptides 25, 975-983. doi: 10.1016/j.peptides.2004.03.009

Trent, N. L., and Menard, J. L. (2013). Lateral septal infusions of the neuropeptide Y Y2 receptor agonist, NPY(13-36) differentially affect different defensive behaviors in male, Long Evans rats. Physiol. Behav. 110-111, 20-29. doi: 10.1016/j.physbeh.2012.12.011

Tschenett, A., Singewald, N., Carli, M., Balducci, C., Salchner, P., Vezzani, A., et al. (2003). Reduced anxiety and improved stress coping ability in mice lacking NPY-Y2 receptors. Eur. J. Neurosci. 18, 143-148. doi: 10.1046/j.14609568.2003.02725.x

Urbano-Marquez, A., Estruch, R., Fernandez-Sola, J., Nicolas, J. M., Pare, J. C., and Rubin, E. (1995). The greater risk of alcoholic cardiomyopathy and myopathy in women compared with men. JAMA 274, 149-154. doi: 10.1001/jama.1995.03530020067034

Voikar, V., Koks, S., Vasar, E., and Rauvala, H. (2001). Strain and gender differences in the behavior of mouse lines commonly used in transgenic studies. Physiol. Behav. 72, 271-281. doi: 10.1016/S0031-9384(00)00405-4

Vong, L., Ye, C., Yang, Z., Choi, B., Chua, S. Jr., and Lowell, B. B. (2011). Leptin action on GABAergic neurons prevents obesity and reduces inhibitory tone to POMC neurons. Neuron 71, 142-154. doi: 10.1016/j.neuron.2011.05.028

Zambello, E., Zanetti, L., Hedou, G. F., Angelici, O., Arban, R., Tasan, R. O. et al. (2010). Neuropeptide Y-Y2 receptor knockout mice: influence of genetic background on anxiety-related behaviors. Neuroscience 176, 420-430. doi: 10.1016/j.neuroscience.2010.10.075

Zhang, H., Sakharkar, A. J., Shi, G., Ugale, R., Prakash, A., and Pandey, S. C. (2010). Neuropeptide Y signaling in the central nucleus of amygdala regulates alcoholdrinking and anxiety-like behaviors of alcohol-preferring rats. Alcohol. Clin. Exp. Res. 34, 451-461. doi: 10.1111/j.1530-0277.2009.01109.x

Zimmerberg, B., and Farley, M. J. (1993). Sex differences in anxiety behavior in rats: role of gonadal hormones. Physiol. Behav. 54, 1119-1124. doi: 10.1016/00319384(93)90335-D

Conflict of Interest Statement: The authors declare that the research was conducted in the absence of any commercial or financial relationships that could be construed as a potential conflict of interest.

Received: 2 October 2013; accepted: 08 December 2013; published online: 25 December 2013.

Citation: McCall NM, Sprow GM, Delpire E, Thiele TE, Kash TL and Pleil KE (2013) Effects of sex and deletion of neuropeptide Y2 receptors from GABAergic neurons on affective and alcohol drinking behaviors in mice. Front. Integr. Neurosci. 7:100. doi: 10.3389/fnint.2013.00100

This article was submitted to the journal Frontiers in Integrative Neuroscience. Copyright (C) 2013 McCall, Sprow, Delpire, Thiele, Kash and Pleil. This is an openaccess article distributed under the terms of the Creative Commons Attribution License $(C C B Y)$. The use, distribution or reproduction in other forums is permitted, provided the original author(s) or licensor are credited and that the original publication in this journal is cited, in accordance with accepted academic practice. No use, distribution or reproduction is permitted which does not comply with these terms. 